\title{
Spectroscopic Investigation (FT-IR, FT-RAMAN, UV and NMR), NBO, NLO Analysis and Fukui Function of 2, 5-Dichloroaniline by DFT Calculations
}

\author{
${ }^{*}$ G.Shakila ${ }^{1}$, Dr.H. Saleem ${ }^{2}$ \\ ${ }^{1}$ Department of Physics, Bharathidasan Government College for Women, Puducherry-605003, India. \\ ${ }^{2}$ Department of Physics, Annamalai University, Annamalainagar-608002, Tamilnadu, India. \\ Corresponding Author: G.Shakila
}

\begin{abstract}
The spectral characterization of 2,5-Dichloro aniline (2,5 DCA) were carried out by using FT-IR, FT-Raman, the NMR and UV-Vis spectroscopic techniques. The simulated vibrational spectra of the molecule are compared with the experimental spectra. The structural optimization has been performed on the title molecule using HF and density functional theory $(D F T)$ with basis sets $6-31+G(d, p)$ and $6-311++G(d, p)$. The optimized bond parameters of 2,5 DCA were compared with the experimental data of related molecule. Using Veda program, the vibrational wave number assignments were made on the basis of total energy distribution (TED) calculations. To study the intra-molecular charge transfers within the molecule, the Lewis (bonding) and Non-Lewis (anti-bonding) calculation was performed. The orbital gap of the molecule was determined from HOMO and LUMO calculations. The Non-linear optical properties of the molecule were studied using first hyperpolarizability calculation. The molecular electrostatic potential (MEP), chemical descriptors and thermo dynamical properties of the molecule have also been calculated and analysed. In addition, the Mulliken atomic charges and the ${ }^{1} \mathrm{H}$ and ${ }^{13} \mathrm{C} N \mathrm{NMR}$ chemical shift values of 2,5 DCA was calculated. Also the local reactivity of the molecule was studied using the Fukui function.
\end{abstract}

Keywords: FT-IR, FT-Raman, NMR, UV analysis and Fukui function.

Date of Submission: 04-07-2017

Date of acceptance: $15-07-2017$

\section{Introduction}

Aniline and its derivatives are widely used in chemical dye industries, to manufacture nano cables in electronic industries, pesticides and also used for several industrial and commercial purposes [1]. Aniline is used in the chemical industry for the synthesis of many compounds such as dye antioxidants, drugs, rubber accelerators etc. Some of the derivatives of aniline molecules are used as local anaesthetics, since the amino group in these molecules plays an important role in the interaction with the receptor. The investigation of the molecular properties and the natures of chemical reaction of Aniline and its derivatives are of great importance. Hence, the study on the molecular structures and the spectral investigation of aniline and substituted anilines are carried out increasingly. The substitution of two chlorine atoms in aniline and the enhanced interaction between the aromatic ring, chlorine atom and the amino group affects the charge distribution in the molecule. This greatly leads to variations in the structural, electronic and vibrational properties [2]. Because of their spectroscopic properties and chemical significance, various spectroscopic studies of halogen and methyl substituted molecules were reported in many literatures [3,8].

Therefore, a complete spectroscopic study of the molecule 2,5 DCA has been reported using A $b$ initio HF and DFT (B3LYP) Calculations. The vibrational assignments and the molecular, thermodynamic properties of 2, 5-DCA was discussed and interpreted.

\section{Experimental Details}

The molecule 2,5DCA is purchased from Sigma-Aldrich chemicals, USA and it was used for the present investigation. The FT-IR spectrum in the range of $4000-400 \mathrm{~cm}^{-1}$ was recorded using $\mathrm{KBr}$ pellet technique with a FT-IR-Shimadzu spectrometer. The spectrum was recorded in Central Instrumentation facility, Pondicherry University. FT-Raman spectrum of the compound was also observed using Bruker IFS 66v spectrophotometer equipped with a FRA 106 FT-Raman module accessory in the region 100-4000 $\mathrm{cm}^{-1}$. The FT-Raman spectrum was recorded in the same laboratory. The UV-Vis absorption spectrum of 2,5 DCA was recorded in the range of 200-500 nm using a Shimadzu - 2600 spectrometer in the Department of Chemistry, Jamal Mohamed College, Thiruchirappalli, Tamilnadu. 


\subsection{Quantum Chemical Calculations}

The entire calculations of 2,5 DCA were performed at HF and B3LYP functional combined with standard 6-31+G and 6-311++G basis sets on a personal computer using Gaussian $09 \mathrm{~W}$ program package. The optimized structural parameters were used in the vibrational frequencies calculation at different level of theories. The output of this program results in the data such as, the theoretical wave numbers, reduced mass, force constant, infrared intensity, Raman activity, and depolarization ratios. To compare the theoretical and the experimental wave numbers, the scaling factors have been introduced. After scaling by suitable scale factors, the deviation from the experimental wave numbers is $\pm 10 \mathrm{~cm}^{-1}$ with a few exceptions. The assignments of calculated vibrational modes were done on basis of the TED calculation using VEDA4 program [9]. Gauss view Program [10] was used for the verification of the vibrational modes assignment from the visual animation.

The electronic transition of the title molecule was calculated from UV-Visible analysis for the optimized molecule with the time dependent DFT at B3LYP/6311++G(d,p) level in gas phase and solvent (DMSO and chloroform). Furthermore, the nonlinear optic (NLO) activity of title molecule such as, the dipole moment, linear polarizability and first hyperpolarizability were calculated. Moreover, the thermodynamic functions namely, the heat capacity, entropy, and enthalpy were investigated for the different temperatures from the B3LYP calculation of the molecule 2,5 DCA. Using the gauge independent atomic orbital method, the ${ }^{1} \mathrm{H}$, ${ }^{13} \mathrm{C}$ nuclear magnetic resonance chemical shifts of the molecule were calculated in chloroform and compared with experimental results.

\subsection{Molecular Geometry:}

\section{Results And Discussion}

The total energy, zero point vibrational energy, rotational constant and entropy obtained by the DFT structure optimization based on B3LYP/6-311++G basis set of 2,5- DCA is listed in Table 1.The optimized molecular structure of the molecule belonging to Cs point group symmetry is depicted in Fig.1. The title compound has two chlorine atoms and amino group connected with Benzene ring. The parameters namely bond lengths, bond angles and dihedral angles at HF/ 6-31+G and B3LYP/ 6-311++G $(\mathrm{d}, \mathrm{p})$ levels are given in the Table .2. These calculated data of 2,5-DCA are compared with the experimental data of aniline and Nitro aniline.

Table 1 The calculated total energy (a.u), zero point vibrational energies (Kcal/mol), rotational constants $(\mathrm{GHz})$ and entropy $\left(\mathrm{cal} / \mathrm{mol} \mathrm{K}^{-1}\right)$ for $2,5 \mathrm{DCA}$.

\begin{tabular}{lc}
\hline Parameters & B3LYP/6-311++G(d,p) \\
\hline Total Energies & -1206.93393495 \\
Zero-point Energy & $61.30972(\mathrm{Kcal} / \mathrm{Mol})$ \\
Rotational constants (GHZ): & 2.92449 \\
& 0.63488 \\
Entropy & 0.52180 \\
Total & 89.618 \\
Translational & 41.137 \\
Rotational & 30.185 \\
Vibrational & 18.296 \\
\hline
\end{tabular}

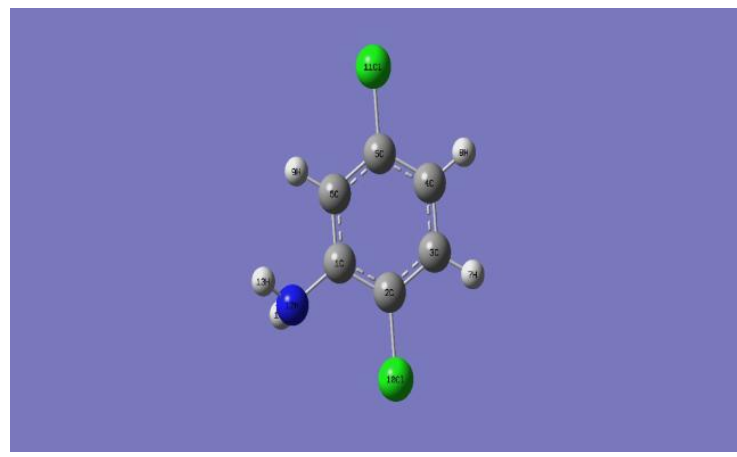

Fig 1. Molecular structure of 2,5 DCA 
From the Table 2, it is evident that majority of the bond lengths are slightly more than the experimental values. Many authors $[11,12]$ investigated the variations in the wave numbers or $\mathrm{C}-\mathrm{H}$ bond length due to distribution of charge on the carbon atom of the benzene ring. The substitution of a halogen for hydrogen in benzene ring decreases the electron density at the ring carbon atom. To verify this, the $\mathrm{C}-\mathrm{H}$ and $\mathrm{C}-\mathrm{Cl}$ bond lengths were compared with the respective experimental values of Aniline and Nitro aniline [13]. The average values of bond lengths of $\mathrm{C}-\mathrm{C}$ and $\mathrm{C}-\mathrm{H}$ calculated by $\mathrm{HF}$ method are 1.387 and $1.074 \AA$, respectively. Also that by B3LYP method is 1.395 and $1.082 \AA$, respectively.

The benzene breakdown due to the elongation of $\mathrm{C} 1-\mathrm{C} 2(\sim 1.40 \AA)$ and $\mathrm{C} 1-\mathrm{C} 6(\sim 1.40 \AA)$ from the remaining $\mathrm{C}-\mathrm{C}$ bond lengths $(\sim 1.39 \AA)$ for the B3LYP/6-311+G (d, p) method. The negative deviation of $\mathrm{C} 2-$ $\mathrm{C} 1-\mathrm{C} 6(117 \circ)$ and positive deviation of $\mathrm{C} 1-\mathrm{C} 2-\mathrm{C} 3\left(121^{\circ}\right)$ from the normal value of $120^{\circ}$ shows that the benzene ring is slightly distorted. The $\mathrm{C}-\mathrm{N}$ bond distance of $1.3823 \AA$ by B3LYP/ 6-311+G (d, p) method shows just $0.02 \AA$ smaller than the experimental value of $1.402 \AA$, for Aniline [13]. This is probably due to the electron withdrawing property of chlorine. Substitution of chlorine atoms at the position of the hydrogen atoms in the ring reduces the electron density at the ring attached to $\mathrm{N}$. Thus, the attraction of ring carbon atom is more on the valence electron cloud of nitrogen atom, causing increase in $\mathrm{C}-\mathrm{N}$ force constant and decrease in the corresponding bond length.

The $\mathrm{C}-\mathrm{Cl}$ bond length increases when the $\mathrm{H}$ atom is replaced by $\mathrm{Cl}$ atom. This is observed even in benzene derivatives [14]. The C2-Cl10 bond length is found to be $1.7467 \AA$ (HF) and $1.7627 \AA$ (B3LYP). The C5-Cl11 bond length is found to be $1.7414 \AA$ (HF) and $1.7591 \AA$ (B3LYP). G.D.Lister et al. [13] calculated this bond length to be $1.784 \AA$ for Aniline by using force field calculations.

\subsection{Vibrational assignments}

The title molecule has 14 atoms and has 36 normal vibrational modes. The modes that are in the plane of the molecule are represented as $\mathbf{A}$ ' and out of plane as $\mathbf{A}$ ', Thus the 36 normal modes of vibrations are distributed as

$$
\Gamma \mathrm{vib}=24 \mathrm{~A}^{\prime}+12 \mathrm{~A}^{\prime \prime}
$$

To study the vibrational assignment of the molecule, the TED calculation is performed and is compared with theoretically scaled wave numbers by B3LYP method. The theoretical and experimental infrared and Raman spectra of 2,5-DCA was shown in Fig.2 and 3 respectively. The observed, scaled theoretical frequencies, the IR Intensities and Raman Activities using DFT (B3LYP) with 6-311++G(d,p) basis set with TEDs were listed in Table 3.

Table 2 Optimized geometric parameters of 2,5 DCA

\begin{tabular}{|c|c|c|c|c|}
\hline Bond parameter & HF/6-31+G(d,p) & B3LYP/6-311++G (d,p) & \multicolumn{2}{|c|}{ Experimental Value } \\
\hline Bond length $(\AA)$ & & & Aniline & Nitro aniline \\
\hline $\mathrm{C} 1-\mathrm{C} 2$ & 1.3939 & 1.4062 & 1.394 & 1.408 \\
\hline C1-C6 & 1.3979 & 1.4055 & 1.397 & 1.415 \\
\hline C1-N12 & 1.38 & 1.3823 & 1.402 & 1.371 \\
\hline $\mathrm{C} 2-\mathrm{C} 3$ & 1.3828 & 1.3878 & 1.396 & 1.377 \\
\hline C2-CL10 & 1.7467 & 1.7627 & 1.745 & \\
\hline C3-C4 & 1.3827 & 1.3918 & - & 1.390 \\
\hline $\mathrm{C} 3-\mathrm{H} 7$ & 1.074 & 1.0826 & - & 0.95 \\
\hline C4-C5 & 1.3848 & 1.3915 & - & 1.395 \\
\hline C4-H8 & 1.0726 & 1.0812 & 1.082 & \\
\hline C5-C6 & 1.3775 & 1.386 & 1.394 & 1.373 \\
\hline C5-CL11 & 1.7414 & 1.7591 & 1.745 & - \\
\hline C6-H9 & 1.0742 & 1.0832 & 1.08 & 0.83 \\
\hline N12-H13 & 0.9946 & 1.0078 & 1.001 & 0.96 \\
\hline N12-H14 & 0.9945 & 1.0087 & - & - \\
\hline Bond angles $\left({ }^{\circ}\right)$ & & & & \\
\hline C2-C1-C6 & 117.5914 & 117.3229 & 118.92 & 118.9 \\
\hline $\mathrm{C} 2-\mathrm{C} 1-\mathrm{N} 12$ & 122.3272 & 121.9738 & - & 121.2 \\
\hline C6-C1-N12 & 120.0341 & 120.6565 & - & 119.9 \\
\hline $\mathrm{C} 1-\mathrm{C} 2-\mathrm{C} 3$ & 121.3307 & 121.6678 & - & 120.8 \\
\hline C1-C2-CL10 & 119.7675 & 119.1054 & - & - \\
\hline C3-C2-CL10 & 118.9016 & 119.2263 & 120.70 & - \\
\hline C2-C3-C4 & 120.8051 & 120.5631 & - & 119.2 \\
\hline C2-C3-H7 & 119.1473 & 119.2867 & - & 118 \\
\hline C4-C3-H7 & 120.0475 & 120.1499 & - & 115.0 \\
\hline C3-C4-C5 & 118.0282 & 118.0976 & - & 121.2 \\
\hline C3-C4-H8 & 121.0094 & 120.9618 & - & - \\
\hline
\end{tabular}



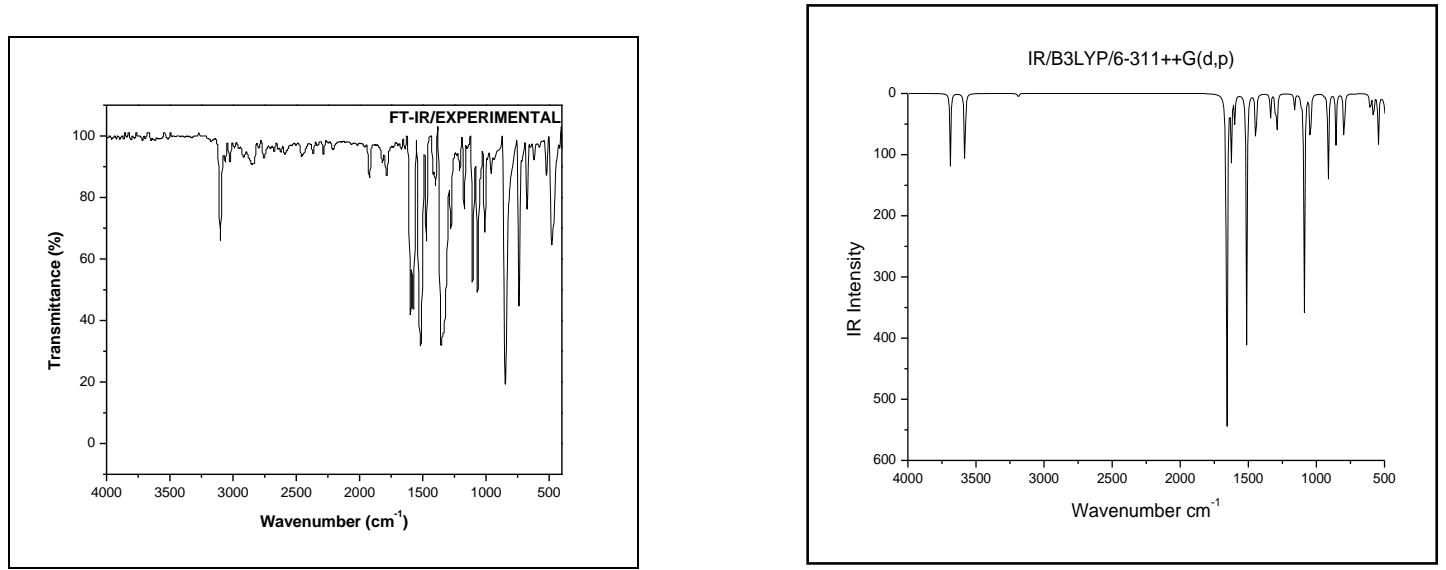

Fig.2 The Theoretical and Experimental IR spectra of 2,5 DCA
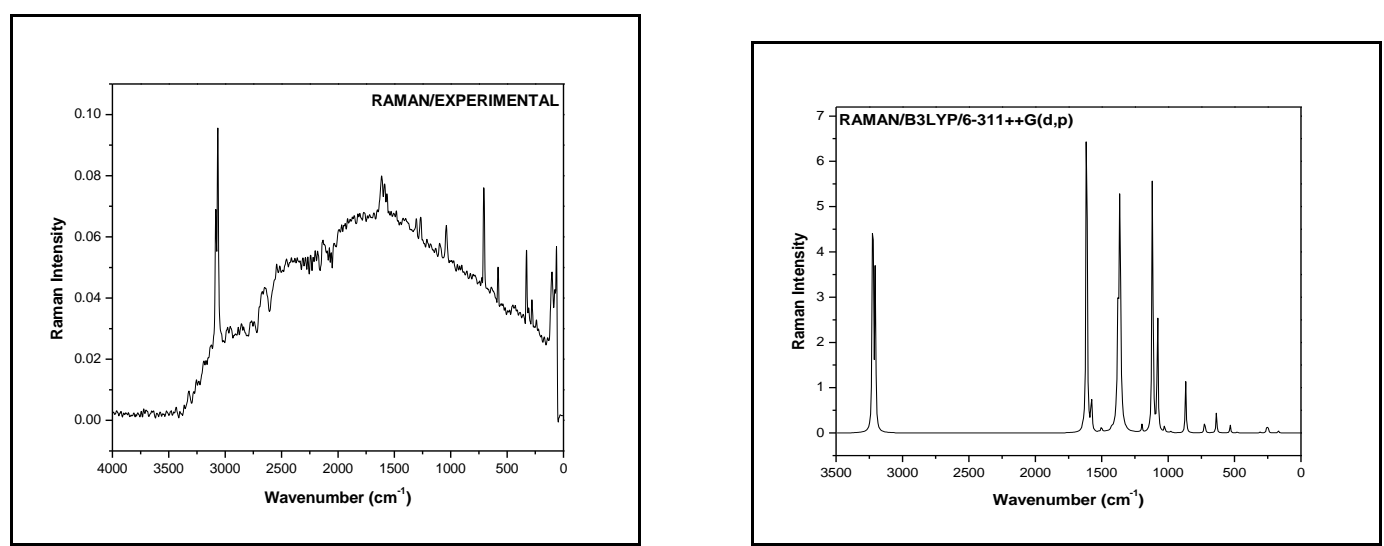

Fig.3 The Theoretical and Experimental Raman spectra of 2,5 DCA

\subsubsection{C-H vibrations}

In aromatic hydrocarbons, various $\mathrm{C}-\mathrm{H}$ stretching vibration usually appear in the region $3100-3000$ $\mathrm{cm}^{-1}$ [15-17]. In 2,5 DCA, three bands at 3221, 3194 and $3188 \mathrm{~cm}^{-1}$ in the IR region were assigned to C-H ring stretching vibrations. The respective calculated unscaled values are 3216,3196 and $3188 \mathrm{~cm}^{-1}$. It is evident that all the $\mathrm{C}-\mathrm{H}$ stretching vibrations in IR region appear in the higher frequency range due to chlorine atom and nitrogen atom. The C-H in-plane bending vibrations in both FT-IR and Raman fall in the region 1290-900 $\mathrm{cm}^{-1}$. The modes at 1516, 1471, 1354, 1277, 1207 and $1117 \mathrm{~cm}^{-1}$ are due to $\mathrm{C}-\mathrm{H}$ in-plane bending vibrations. The modes at 1516, 1471 and $1354 \mathrm{~cm}^{-1}$ are outside the expected range, due to $\mathrm{Cl}$ atom and $\mathrm{NH}_{2}$ group. The band at $1516 \mathrm{~cm}^{-1}$ is described as a mixed mode (mode no.28) with PED $16 \%$ and $1471 \mathrm{~cm}^{-1}$ (mode no.27) with TED $21 \%$. From TED calculations it is observed that all six C-H in-plane bending vibrations are described as mixed modes. Compared with the theoretically computed unscaled frequencies by B3LYP/6-311++G (d, p) method for $\mathrm{C}-\mathrm{H}$ in-plane bending vibrations, the corresponding observed vibrations are obtained in the higher frequency end except the value at $1516 \mathrm{~cm}^{-1}$. This is because of the chlorine atom and nitrogen atom. For the mode no.24 which has IR band at $1277 \mathrm{~cm}^{-1}$, Raman band is also produced at $1266 \mathrm{~cm}^{-1}$.

The C-H out-of-plane bending vibrations of Aniline derivatives appear in the range $1000-675 \mathrm{~cm}^{-1}[18$ 20]. In this title compound, one IR band at $944 \mathrm{~cm}^{-1}$ is observed as C-H out-of-plane bending vibrations. This C$\mathrm{H}$ out-of-plane bending vibration agrees well with the literature values and also well supported by TED values.

\subsubsection{Ring vibrations}

The ring $C=C$ and $C-C$ stretching vibrations, mostly appear in the region $1200-1625 \mathrm{~cm}^{-1}$ [21]. The $\mathrm{C}=\mathrm{C}$ stretching vibrational mode of the present compound are observed at $1638,1597,1516,1471$ and1399 $\mathrm{cm}^{-1}$ in the IR region. All these assignments coincide well with the literature data and calculated unscaled values. The bands at 1277,1207 and 1117,1084 and $1066 \mathrm{~cm}^{-1}$ are due to $\mathrm{C}-\mathrm{C}$ stretching vibrations. The $\mathrm{C}=\mathrm{C}$ stretching vibrations, shifts to the higher wave number range and it is due to the presence of $\mathrm{NH}_{2}$ atoms. There is a considerable decrease in wave numbers of $\mathrm{C}-\mathrm{C}$ stretching vibrations, when compared to literature values.

Table 3 Detailed vibrational assignment of 2,5 DCA using B3LYP/6-311++G(d,p) level along with TED calculation. 
Spectroscopic Investigation (FT-IR, FT-RAMAN, UV and NMR), NBO, NLO Analysis and Fukui

\begin{tabular}{|c|c|c|c|c|c|c|c|}
\hline \multirow[t]{3}{*}{ S.No } & \multirow{2}{*}{\multicolumn{2}{|c|}{$\begin{array}{c}\text { Calculated } \\
\text { Frequencies }\left(\mathrm{cm}^{-1}\right)\end{array}$}} & \multirow{2}{*}{\multicolumn{2}{|c|}{$\begin{array}{c}\text { Observed } \\
\text { Frequencies }\left(\mathrm{cm}^{-1}\right)\end{array}$}} & \multirow{3}{*}{$\begin{array}{c}\text { IR } \\
\text { Intensity } \\
\text { Abs. }\end{array}$} & \multirow{3}{*}{$\begin{array}{c}\text { Raman } \\
\text { Intensity } \\
\text { Abs. }\end{array}$} & \multirow{3}{*}{ Vibrational assignments } \\
\hline & & & & & & & \\
\hline & $\begin{array}{c}\text { Un } \\
\text { Scaled }\end{array}$ & Scaled & FT-IR & $\begin{array}{c}\text { FT- } \\
\text { Raman }\end{array}$ & & & \\
\hline 1 & 98 & 94.75 & 100.00 & 101.61 & 0.42 & 0.23 & $\begin{array}{l}\tau \mathrm{C}_{1} \mathrm{C}_{6} \mathrm{C}_{4} \mathrm{C}_{5}(25)+\tau \mathrm{C}_{1} \mathrm{C}_{6} \mathrm{C}_{2} \mathrm{C}_{3}(40)+ \\
\Gamma \mathrm{CL}_{10} \mathrm{C}_{1} \mathrm{C}_{3} \mathrm{C}_{2}(17)+\Gamma \mathrm{CL}_{11} \mathrm{C}_{4} \mathrm{C}_{5} \mathrm{C}_{6}(15)\end{array}$ \\
\hline 2 & 206 & 199.16 & 197.00 & & 4.14 & 0.59 & $\begin{array}{l}\tau \mathrm{C}_{1} \mathrm{C}_{6} \mathrm{C}_{4} \mathrm{C}_{5}(22)+\tau \mathrm{C}_{1} \mathrm{C}_{6} \mathrm{C}_{2} \mathrm{C}_{3}(34)+ \\
\Gamma \mathrm{CL}_{11} \mathrm{C}_{4} \mathrm{C}_{5} \mathrm{C}_{6}(18)+\Gamma \mathrm{N}_{12} \mathrm{C}_{1} \mathrm{C}_{2} \mathrm{C}_{6}(13)\end{array}$ \\
\hline 3 & 220 & 212.70 & 224.00 & & 0.45 & 0.06 & $\beta \mathrm{C}_{3} \mathrm{C}_{2} \mathrm{CL}_{10}(38)+\beta \mathrm{C}_{6} \mathrm{C}_{5} \mathrm{CL}_{11}(47)$ \\
\hline 4 & 272 & 262.86 & 280.00 & 279.38 & 1.71 & 2.00 & $\begin{array}{l}\beta \mathrm{C}_{6} \mathrm{C}_{1} \mathrm{~N}_{12}(30)+\beta \mathrm{C}_{3} \mathrm{C}_{2} \mathrm{CL}_{10}(31)+ \\
\beta \mathrm{C}_{6} \mathrm{C}_{5} \mathrm{CL}_{11}(17)\end{array}$ \\
\hline 5 & 299 & 288.98 & 297.00 & & 6.64 & 0.20 & $\begin{array}{l}\tau \mathrm{C}_{2} \mathrm{C}_{3} \mathrm{C}_{4} \mathrm{C}_{5}(15)+\Gamma \mathrm{CL}_{10} \mathrm{C}_{1} \mathrm{C}_{3} \mathrm{C}_{2}(46)+ \\
\Gamma \mathrm{C}_{4} \mathrm{C}_{5} \mathrm{C}_{6} \mathrm{CL}_{11}(22)\end{array}$ \\
\hline 6 & 326 & 315.46 & & 327.63 & 0.08 & 10.39 & $v \mathrm{CL}_{10} \mathrm{C}_{2}(23)+v \mathrm{CL}_{11} \mathrm{C}_{5}(22)+\beta \mathrm{C}_{6} \mathrm{C}_{5} \mathrm{C}_{4}(25)$ \\
\hline 7 & 360 & 348.48 & 367.00 & & 14.66 & 0.48 & $\tau \mathrm{N}_{12} \mathrm{H}_{13} \mathrm{C}_{1} \mathrm{C}_{2}(46)+\tau \mathrm{H}_{14} \mathrm{C}_{1} \mathrm{C}_{2} \mathrm{C}_{1} \mathrm{~N}_{12}(35)$ \\
\hline 8 & 447 & 432.62 & 448.00 & & 58.32 & 0.22 & $\begin{array}{l}\tau \mathrm{C}_{1} \mathrm{C}_{6} \mathrm{C}_{4} \mathrm{C}_{5}(22)+\tau \mathrm{C}_{2} \mathrm{C}_{3} \mathrm{C}_{4} \mathrm{C}_{5}(25)+ \\
\Gamma \mathrm{N}_{12} \mathrm{C}_{1} \mathrm{C}_{2} \mathrm{C}_{6}(11)\end{array}$ \\
\hline 9 & 451 & 436.32 & & & 11.88 & 1.17 & $\begin{array}{l}\nu \mathrm{CL}_{11} \mathrm{C}_{5}(14)+\beta \mathrm{C}_{6} \mathrm{C}_{1} \mathrm{~N}_{12}(37)+ \\
\beta \mathrm{C}_{6} \mathrm{C}_{5} \mathrm{CL}_{11}(13)+\beta \mathrm{C}_{3} \mathrm{C}_{2} \mathrm{CL}_{10}(12)\end{array}$ \\
\hline 10 & 476 & 460.20 & 479.40 & & 206.23 & 1.33 & $\tau \mathrm{N}_{12} \mathrm{H}_{13} \mathrm{C}_{1} \mathrm{C}_{2}(24)+\tau \mathrm{H}_{14} \mathrm{C}_{1} \mathrm{C}_{2} \mathrm{C}_{1} \mathrm{~N}_{12}(45)$ \\
\hline 11 & 545 & 526.91 & 521.50 & & 26.16 & 2.83 & $\begin{array}{l}v \mathrm{CL}_{10} \mathrm{C}_{2}(16)+v \mathrm{CL}_{11} \mathrm{C}_{5}(15)+\beta \mathrm{C}_{1} \mathrm{C}_{2} \mathrm{C}_{6}(26)+ \\
\beta \mathrm{C}_{6} \mathrm{C}_{1} \mathrm{~N}_{12}(13)\end{array}$ \\
\hline 12 & 580 & 560.74 & & 580.25 & 15.80 & 7.52 & $v \mathrm{CL}_{10} \mathrm{C}_{2}(21)+\beta \mathrm{C}_{4} \mathrm{C}_{3} \mathrm{C}_{2}(16)+\beta \mathrm{C}_{2} \mathrm{C}_{1} \mathrm{C}_{6}(26)$ \\
\hline 13 & 604 & 584.40 & 620.50 & & 10.53 & 0.35 & $\begin{array}{l}\tau \mathrm{H}_{8} \mathrm{C}_{4} \mathrm{C}_{5} \mathrm{C}_{6}(16)+\tau \mathrm{C}_{2} \mathrm{C}_{3} \mathrm{C}_{4} \mathrm{C}_{5}(15)+ \\
\Gamma \mathrm{CL}_{11} \mathrm{C}_{4} \mathrm{C}_{5} \mathrm{C}_{6}(26)+\Gamma \mathrm{N}_{12} \mathrm{C}_{1} \mathrm{C}_{2} \mathrm{C}_{6}(25)\end{array}$ \\
\hline 14 & 716 & 692.52 & & 705.78 & 0.47 & 19.37 & $v \mathrm{C}_{1} \mathrm{C}_{2}(15)+\beta \mathrm{C}_{4} \mathrm{C}_{5} \mathrm{C}_{6}(14)+\beta \mathrm{C}_{4} \mathrm{C}_{3} \mathrm{C}_{2}(30)$ \\
\hline 15 & 734 & 709.31 & 738.70 & & 0.20 & 1.33 & $\begin{array}{l}\left.\tau \mathrm{N}_{12} \mathrm{H}_{9} \mathrm{C}_{1} \mathrm{C}_{6}(12)\right)+\tau \mathrm{C}_{1} \mathrm{C}_{6} \mathrm{C}_{4} \mathrm{C}_{5}(10)+ \\
\tau \mathrm{C}_{2} \mathrm{C}_{3} \mathrm{C}_{4} \mathrm{C}_{5}(18)+\Gamma \mathrm{N}_{12} \mathrm{C}_{1} \mathrm{C}_{2} \mathrm{C}_{6}(34)\end{array}$ \\
\hline 16 & 797 & 770.47 & 799.00 & & 30.82 & 0.16 & $\Gamma \mathrm{C}_{3} \mathrm{C}_{4} \mathrm{C}_{5} \mathrm{H}_{7}(28)+\tau \mathrm{H}_{8} \mathrm{C}_{4} \mathrm{C}_{5} \mathrm{CL}_{11}(61)$ \\
\hline 17 & 856 & 827.48 & 847.20 & & 24.12 & 0.36 & $\tau \mathrm{C}_{6} \mathrm{C}_{1} \mathrm{~N}_{12} \mathrm{H}_{9}(77)$ \\
\hline 18 & 913 & 882.99 & 959.30 & & 44.58 & 1.16 & $v \mathrm{~N}_{12} \mathrm{C}_{1}(18)+v \mathrm{CL}_{11} \mathrm{C}_{5}(18)+\beta \mathrm{C}_{4} \mathrm{C}_{5} \mathrm{C}_{6}(27)$ \\
\hline 19 & 944 & 912.85 & 1010.50 & & 0.74 & 0.14 & $\begin{array}{l}\tau \mathrm{C}_{3} \mathrm{C}_{4} \mathrm{C}_{5} \mathrm{H}_{7}(50)+\tau \mathrm{H}_{8} \mathrm{C}_{4} \mathrm{C}_{5} \mathrm{C}_{6}(27) \\
+\tau \mathrm{C}_{2} \mathrm{C}_{3} \mathrm{C}_{4} \mathrm{C}_{5}(16)\end{array}$ \\
\hline 20 & 1044 & 1009.79 & 1066.10 & 1039.68 & 32.83 & 21.66 & $\begin{array}{l}v \mathrm{C}_{1} \mathrm{C}_{6}(20)+v \mathrm{CL}_{10} \mathrm{C}_{2}(11)+\beta \mathrm{C}_{4} \mathrm{C}_{3} \mathrm{C}_{2}(12)+ \\
\beta \mathrm{C}_{2} \mathrm{C}_{1} \mathrm{C}_{6}(14)\end{array}$ \\
\hline 21 & 1089 & 1052.66 & 1084.00 & & 107.57 & 0.34 & $v \mathrm{C}_{1} \mathrm{C}_{2}(14)+\beta \mathrm{H}_{13} \mathrm{~N}_{12} \mathrm{C}_{1}(33)$ \\
\hline 22 & 1113 & 1076.41 & 1117.00 & & 3.87 & 14.75 & $\begin{array}{l}v \mathrm{C}_{4} \mathrm{C}_{3}(16)+v \mathrm{C}_{5} \mathrm{C}_{4}(14)+\beta \mathrm{H}_{13} \mathrm{~N}_{12} \mathrm{C}_{1}(15) \\
+\beta \mathrm{H}_{9} \mathrm{C}_{6} \mathrm{C}_{1}(22)\end{array}$ \\
\hline 23 & 1161 & 1122.54 & 1207.90 & & 7.82 & 1.43 & $v \mathrm{C}_{4} \mathrm{C}_{3}(21)+\beta \mathrm{H}_{7} \mathrm{C}_{3} \mathrm{C}_{4}(15)+\beta \mathrm{H}_{8} \mathrm{C}_{4} \mathrm{C}_{5}(38)$ \\
\hline 24 & 1288 & 1245.33 & 1277.90 & 1266.72 & 15.56 & 7.71 & $\left.v \mathrm{C}_{2} \mathrm{C}_{3}(33)\right)+v \mathrm{~N}_{12} \mathrm{C}_{1}(18)+\beta \mathrm{H}_{7} \mathrm{C}_{3} \mathrm{C}_{4}(28)$ \\
\hline 25 & 1300 & 1257.07 & 1354.70 & & 15.27 & 4.28 & $\left.v \mathrm{~N}_{12} \mathrm{C}_{1}(10)\right)+\beta \mathrm{H}_{8} \mathrm{C}_{4} \mathrm{C}_{5}(15)+\beta \mathrm{H}_{9} \mathrm{C}_{6} \mathrm{C}_{1}(40)$ \\
\hline 26 & 1337 & 1292.72 & 1399.30 & & 12.12 & 6.82 & $\begin{array}{l}v \mathrm{C}_{6} \mathrm{C}_{5}(19)+v \mathrm{C}_{4} \mathrm{C}_{3}(15)+v \mathrm{C}_{5} \mathrm{C}_{4}(11) \\
+v \mathrm{C}_{1} \mathrm{C}_{2}(16)\end{array}$ \\
\hline 27 & 1445 & 1396.64 & 1471.20 & & 33.76 & 0.48 & $\begin{array}{l}v \mathrm{C}_{5} \mathrm{C}_{6}(18)+v \mathrm{C}_{1} \mathrm{C}_{6}(15)+v \mathrm{~N}_{12} \mathrm{C}_{1}(14)+ \\
\beta \mathrm{H}_{8} \mathrm{C}_{4} \mathrm{C}_{5}(21)\end{array}$ \\
\hline 28 & 1512 & 1461.75 & 1516.90 & & 118.71 & 1.94 & $\begin{array}{l}v \mathrm{C}_{2} \mathrm{C}_{3}(11)+v \mathrm{C}_{4} \mathrm{C}_{5}(11)+\beta \mathrm{H}_{7} \mathrm{C}_{3} \mathrm{C}_{4}(21)+ \\
\beta \mathrm{H}_{9} \mathrm{C}_{6} \mathrm{C}_{1}(16)\end{array}$ \\
\hline 29 & 1599 & 1546.27 & 1597.20 & & 12.97 & 11.12 & $\begin{array}{l}v \mathrm{C}_{3} \mathrm{C}_{4}(19)+v \mathrm{C}_{4} \mathrm{C}_{5}(18)+v \mathrm{C}_{1} \mathrm{C}_{6}(18)+ \\
v \mathrm{C}_{1} \mathrm{C}_{2}(17)\end{array}$ \\
\hline 30 & 1624 & 1570.45 & 1638.90 & & 29.88 & 18.96 & $v \mathrm{C}_{2} \mathrm{C}_{3}(18)+v \mathrm{C}_{5} \mathrm{C}_{6}(20)+\beta \mathrm{H}_{13} \mathrm{~N}_{12} \mathrm{H}_{14}(19)$ \\
\hline 31 & 1658 & 1603.20 & 1665.00 & 1612.36 & 206.51 & 22.98 & $\beta \mathrm{H}_{13} \mathrm{~N}_{12} \mathrm{H}_{14}(64)$ \\
\hline 32 & 3188 & 3081.69 & 3188.00 & & 2.18 & 66.57 & $v \mathrm{C}_{6} \mathrm{H}_{9}(99)$ \\
\hline 33 & 3196 & 3089.50 & 3194.00 & & 0.60 & 70.55 & $v \mathrm{C}_{3} \mathrm{H}_{7}(85)+v \mathrm{C}_{4} \mathrm{H}_{8}(14)$ \\
\hline 34 & 3216 & 3211.00 & 3221.00 & & 0.14 & 128.76 & $v \mathrm{C}_{3} \mathrm{H}_{7}(14)+v \mathrm{C}_{4} \mathrm{H}_{8}(86)$ \\
\hline 35 & 3582 & 3589.00 & 3576.00 & & 42.04 & 170.12 & $\left.v \mathrm{~N}_{12} \mathrm{H}_{13}(43)\right)+v \mathrm{~N}_{12} \mathrm{H}_{14}(56)$ \\
\hline 36 & 3688 & 3693.00 & 3699.00 & & 34.41 & 40.77 & $v \mathrm{~N}_{12} \mathrm{H}_{13}(56)+v \mathrm{~N}_{12} \mathrm{H}_{14}(43)$ \\
\hline
\end{tabular}

The $\beta_{4} \mathrm{C}_{5} \mathrm{C}_{6}(27) \mathrm{CCC}$ in-plane bending mode in FT-IR region is observed at $959 \mathrm{~cm}^{-1}$ (mode no.18) and that corresponding to calculation is $913 \mathrm{~cm}^{-1}$. The $\beta C_{1} C_{2} C_{6}(26)$ and $\beta C_{2} C_{3} C_{4}(16)$ vibrations are observed at $580 \mathrm{~cm}^{-1}$ in FT-Raman and the corresponding calculated value is $580 \mathrm{~cm}^{-1}$ (mode no.12). The $\beta \mathrm{C}_{4} \mathrm{C}_{5} \mathrm{C}_{6}(14)$ and $\beta C_{4} C_{3} C_{2}$ (30) vibrations is observed at $705 \mathrm{~cm}^{-1}$ (mode no.14) in FT-Raman region and the $\beta C_{1} C_{2} C_{6}(26)$ vibration is observed $521 \mathrm{~cm}^{-1}$ (mode no.11) in FT-IR region and the respective theoretical value is $545 \mathrm{~cm}^{-1}$. Also the $\beta_{6} C_{5} C_{4}(25)$ vibration is observed in FT-Raman region at $327 \mathrm{~cm}^{-1}$ and that of the calculated value is $326 \mathrm{~cm}^{-1}$ (mode no.6). The CCC in-plane bending vibrations are in excellent agreement with the literature data [22].

The CCC FT-IR twisting vibrations are observed at 1010,620 and297 $\mathrm{cm}^{-1}$ and the respective calculated values are 944, 604 and $299 \mathrm{~cm}^{-1}$ (mode nos.19, 13 and 5). The $\tau \mathrm{C}_{3} \mathrm{C}_{4} \mathrm{C}_{5} \mathrm{H}_{7}$ (50) and $\tau \mathrm{H}_{8} \mathrm{C}_{4} \mathrm{C}_{5} \mathrm{C}_{6}$ (27) vibrations also contributes to the mode no.19.The $\tau \mathrm{H}_{8} \mathrm{C}_{4} \mathrm{C}_{5} \mathrm{C}_{6}$ (16) and $\tau \mathrm{C}_{2} \mathrm{C}_{3} \mathrm{C}_{4} \mathrm{C}_{5}$ (15) contributes to wave number 620 
$\mathrm{cm}^{-1}$ (mode no.13). The TED contribution of $\mathrm{C} 1 \mathrm{C} 6 \mathrm{C} 4 \mathrm{C} 5$ twisting vibration is $47 \%$ and that of the $\mathrm{C}_{1} \mathrm{C}_{6} \mathrm{C}_{2} \mathrm{C}_{3}$ twisting vibration is $74 \%$.

\subsection{3. $\mathrm{N}-\mathrm{H}$ vibrations}

In aromatic compounds, $\mathrm{N}-\mathrm{H}$ stretching vibration mostly occur in the region $3500-3300 \mathrm{~cm}^{-1}$. The anti symmetric $\mathrm{NH}_{2}$ stretching vibrations is observed in the range $3500-3420 \mathrm{~cm}^{-1}$, while the symmetric stretching appeared in the range $3420-3340 \mathrm{~cm}^{-1}$ [23-26]. The two $\mathrm{NH}_{2}$ anti symmetric stretching vibrations are observed in IR spectra at 3699 and $3576 \mathrm{~cm}^{-1}$, respectively in this study. The theoretical values are 3688 and $3582 \mathrm{~cm}^{-1}$ (mode no.36 and 35) respectively. The TED of both of these modes is contributing $99 \%$ for the anti symmetric $\mathrm{NH}_{2}$ stretching vibrations. The assignment proposed in this case is in line with the earlier works and it is a unique occurrence of $\mathrm{NH}_{2}$.

For aromatic compounds, the in-plane bending deformation vibration of the $\mathrm{NH}_{2}$ group appear in the region 1650-1580 $\mathrm{cm}^{-1}$ [27]. Two bands are observed in this case in IR region at 1665 and $1638 \mathrm{~cm}^{-1}$ (mode no.31 and 30) for this $\mathrm{NH}_{2}$ in-plane bending. The out-of-plane $\mathrm{NH}_{2}$ deformation vibration is usually observed in the region $775-660 \mathrm{~cm}^{1}$ [28]. The $\mathrm{NH}_{2}$ deformation is found at $847 \mathrm{~cm}^{-1}$ (mode no.17) in this study. The wave number value of this vibration is higher than the literature value, and it may be due to the substitute of $\mathrm{Cl}$ atom. Also the modes observed at 738 and $479 \mathrm{~cm}^{-1}$ (mode no.15 and 10) are attributed toNH $\mathrm{H}_{2}$ twisting vibration and the corresponding theoretical value is 734 and $476 \mathrm{~cm}^{-1}$. The rocking mode (mode no.21) is also observed at $1084 \mathrm{~cm}^{-1}$ in the FT-IR region. Also all the assignments of $\mathrm{NH}_{2}$ group are in line with the literature data (23-26).

\subsubsection{Carbon-nitrogen vibrations}

The C-N stretching vibrations of amino group appear in the region 1382-1266 $\mathrm{cm}^{-1}$ [29-31].The FT-IR C-N stretching band is observed at 1277 and $1354 \mathrm{~cm}^{-1}$ and the FT-Raman at $1266 \mathrm{~cm}^{-1}$. These assignments agree well with the reported values. The TED calculation of C-N stretching predicts that, these modes are mixed modes. The twisting mode of $\mathrm{C}_{6} \mathrm{C}_{1} \mathrm{~N}_{12} \mathrm{H}_{9}$ is observed at $847 \mathrm{~cm}^{-1}$ in FT-IR region with TED value of $77 \%$ and it is a pure mode (mode no.17).

\subsubsection{C-Cl vibration}

According to earlier works [32-35], strong characteristic absorptions due to the $\mathrm{C}-\mathrm{Cl}$ stretching motion are found at 1066, 959 and $521 \mathrm{~cm}^{-1}$ in FT-IR (mode no.20, 18 and 11) and in FT-Raman at $580 \mathrm{~cm}^{-1}$ (mode no.12).They are produced as a mixed mode because of the substitution of heavy atoms. But the C-Br stretching vibration gives generally strong band in the region $650-485 \mathrm{~cm}^{-1}$ [36-38]. The bands appearing at 280 and $224 \mathrm{~cm}^{-1}$ (mode no.4\&3) are due to C-Cl in-plane vibration.and the out-plane of C-Cl is observed at 297,197 and $100 \mathrm{~cm}^{-1}$ (mode no.5,2\&1). This observation indicates that the $\mathrm{C}-\mathrm{Cl}$ in-plane and out-plane bending vibrations are deviated appreciably and influenced by the substitution in the ring.

\subsection{Homo-Lumo analysis}

The highest occupied molecular orbitals (HOMOs) and lowest unoccupied molecular orbitals (LUMOs) are called frontier molecular orbitals. The HOMO-LUMO are the main orbitals responsible for chemical stabiity. The HOMO energy describes the ability to donate an electron and LUMO energy describes the ability to obtain an electron. The orbital gap between HOMO and LUMO is an important parameter in determining the molecular chemical stability [39], Optical properties [40] and biological activity [41], Kinetic stability and chemical softness-hardness of a compound. The chemical hardness is a good indicator of the chemical stability. The small orbital gap of the molecule is associated with high chemical reactivity and low kinetic stability.

The HOMO-LUMO orbitals of 2,5 DCA calculated in gas phase using B3LYP/6-311++G(d,p) is shown in Fig.4. In addition, HOMO-2, HOMO-1, LUMO+2 and LUMO+1 molecular orbitals were represented in the Fig .4. The calculated energy values of HUMO, HOMO-1 and HUMO-2 are $-6.2667 \mathrm{eV},-7.0563 \mathrm{eV}$ and $8.6288 \mathrm{eV}$ respectively. The calculated energy values of LUMO, LUMO-1 and LUMO-2 are $-0.9901 \mathrm{eV}$,$0.5518 \mathrm{eV}$ and $-0.4233 \mathrm{eV}$ respectively. The energy gap value between the HOMO and LUMO is $5.2766 \mathrm{eV}$.

The green and red colors represent positive phase and negative phase respectively. It is clear from the figure that, the LUMO of the compound represents charge density localized on the ring, but HOMO represents charge distribution on the entire molecule. Both the HOMO and LUMO are mostly antibonding type orbitals. 


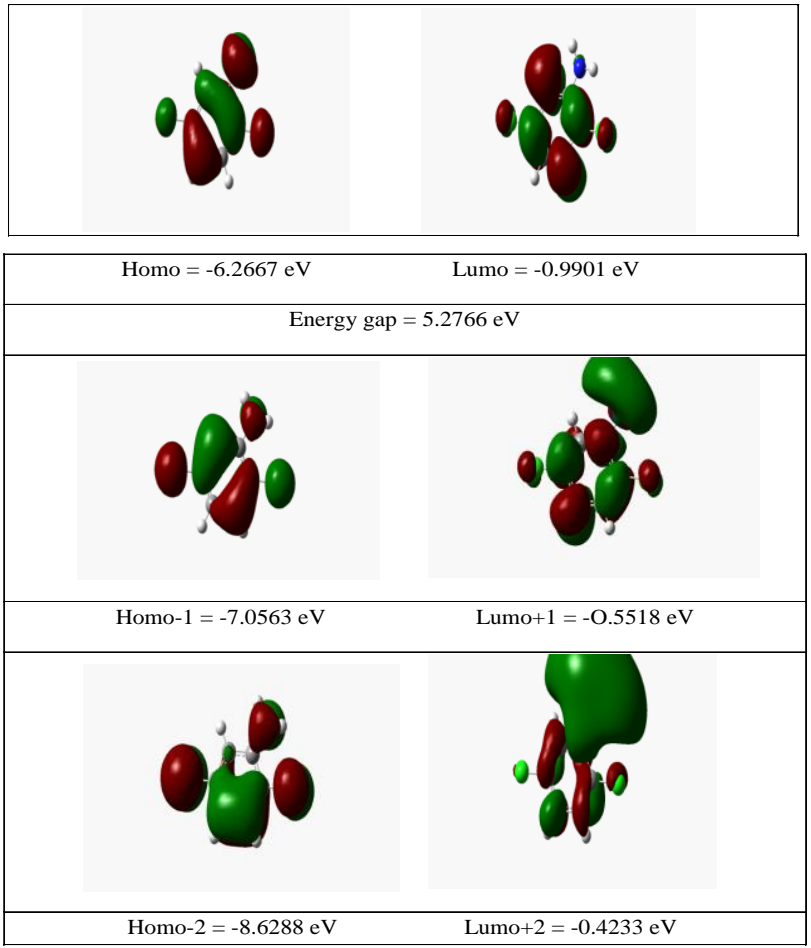

Fig.4 The Homo-Lumo diagram of 2,5DCA

\subsection{Global softness and Local region reactivity}

Molecular charge distribution, molecular orbital surfaces and Homo-Lumo energies are used as reactivity descriptors in DFT study. Besides these reactivity descriptors, there are a set of the chemical reactivity descriptors of molecules $[42,43]$ and they are calculated using koopman's theorem for closed-shell molecules as follows: The global hardness of the molecule is the measure of resistance of an atom to a charge transfer and is given by:

$$
\eta=(\mathrm{I}-\mathrm{A}) / 2
$$

The chemical potential of the molecule is:

$$
\mu=-(\mathrm{I}+\mathrm{A}) / 2
$$

The global softness of the molecule describes the capacity of an atom or group of atoms to receive electrons and is defined by:

$$
S=1 / 2 \eta
$$

The electro negativity of the molecule is the measure of ability of an electron or group of atoms to attract electrons towards it and is given by:

$$
\chi=(\mathrm{I}+\mathrm{A}) / 2
$$

The electrophilicity index of the molecule is:

$$
\omega=\mu^{2} / 2 \eta
$$

A high value of electrophilicity index describes a good electrophile, while a small value of electrophilicity index describes a good nucleophile. Where A is the ionization potential and I is the electron affinity of the molecule. I and A can be defined through HOMO and LUMO orbital energies as I=- $\mathrm{E}_{\text {номо }}$ and

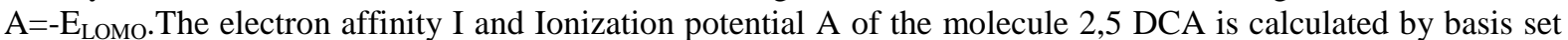
B3LYP/6-311++G(d,p). The values of the softness, hardness, chemical potential, electro negativity and, electrophilicity index of the molecule is calculated as $0.1895 \mathrm{eV}^{-1}, 2.6383 \mathrm{eV},-3.6284 \mathrm{eV}, 3.6284 \mathrm{eV}$, and $2.4950 \mathrm{eV}$ respectively. The soft molecule has a small HOMO-LUMO gap and that of the hard molecule is large. The hard molecules are not easily polarizable than soft one, since they require more energy to excite the levels. 
Fukui indices are measurement of chemical reactivity, indicator of reactive regions and the nucleophilic and electrophilic reaction of the molecules. The regions of the molecule where the fukui function are large are chemically softer than the regions where the fukui function is small. It is also used to recognize the electron acceptor center and donor centers. If $\mathrm{f}+$ for any given site is positive, then it is the preferred site for nucleophilic attack and the negative value of $\mathrm{f}$ - implies electrophilic attack.

The fukui function for addition of electron to a molecule is given by:

$$
f_{+}(r)=\rho_{N+1}(r)-\rho_{N}(r)
$$

The fukui function for removal of electron from a molecule is given by:

$$
f-(r)=\rho_{N}(r)-\rho_{N-1}(r)
$$

The $\mathrm{f}_{+}$function represents the initial part of a nucleophilic reaction. The $\mathrm{f}-$, on the other hand, represents the initial part of an electrophilic reaction. The fukui function (f), global and local softness (S) and global and local electrophilicity index $(\omega)$ of 2,5 DCA is presented in Table 4.From the Table, it is seen that the atoms $\mathrm{C} 1, \mathrm{C} 3$ and $\mathrm{C} 6$ are good nucleophiles having negative local electrophilic index $\Delta \omega$ and they are ready to donate electron pair to form a bond. That is they are ready for electrophilic attack. The atoms C2,C4 and C5 are good electrophiles having positive local electrophilic index $\Delta \omega$ and they are ready to accept electron pair to a form a bond. That is they are ready for nucleophilic attack.

\begin{tabular}{|c|c|c|c|c|}
\hline$f+=(q+1)-q$ & $f-=q-(q-1)$ & $\Delta \mathbf{f}=(\mathbf{f}+)-(\mathbf{f}-)$ & $\Delta S=\Delta f S_{g s}$ & $\Delta \omega=\Delta \mathbf{f} \omega_{\mathrm{ei}}$ \\
\hline-0.764744 & 0.546898 & -1.311642 & -0.2485562 & -3.272547 \\
\hline 0.681082 & -0.635724 & 1.316806 & 0.24953474 & 3.285431 \\
\hline 0.373258 & 0.541425 & -0.168167 & -0.0318676 & -0.419577 \\
\hline 0.148295 & -0.228919 & 0.377214 & 0.07148205 & 0.9411489 \\
\hline-0.005294 & -1.462288 & 1.456994 & 0.27610036 & 3.6352 \\
\hline-0.262823 & 0.151584 & -0.414407 & -0.0785301 & -1.033945 \\
\hline
\end{tabular}

Table 4: Fukui function and global and local softness, and electrophilicity index of

$\Delta \mathrm{S}=$ local softness, $\mathrm{S}_{\mathrm{gs}}$ global softeness; $-\Delta \omega$ local electophilic index, $\omega_{\mathrm{gei}}{ }^{-}$global electrophilic index.

Also the Gauss sum 2.2 program is used to calculate the group contribution to molecular orbitals and to represent the density of states DOS spectrum of 2,5 DCA. It is shown in Fig.5. The spectrum is used to explain the contribution of electrons to the conduction and valence band. The spectrum gives idea about how many states are available at certain energy states. The lines at the starting end of the energy axis of the plot that is from $-20 \mathrm{ev}$ to $-5 \mathrm{ev}$, are called filled orbital and from $-5 \mathrm{ev}$ to $0 \mathrm{ev}$, are called virtual orbital. The virtual orbital are not occupied and are also called acceptor orbital, whereas the filled orbital are called donor orbital. A high intensity DOS at a specific energy levels means that there are many states available for occupation. A DOS of zero intensity represents that no states can be occupied by the system. The variation in the peak height indicates the movement of electrons between the $\mathrm{C}=\mathrm{C}$ and $\mathrm{C}-\mathrm{C}$ in the ring of the molecule.

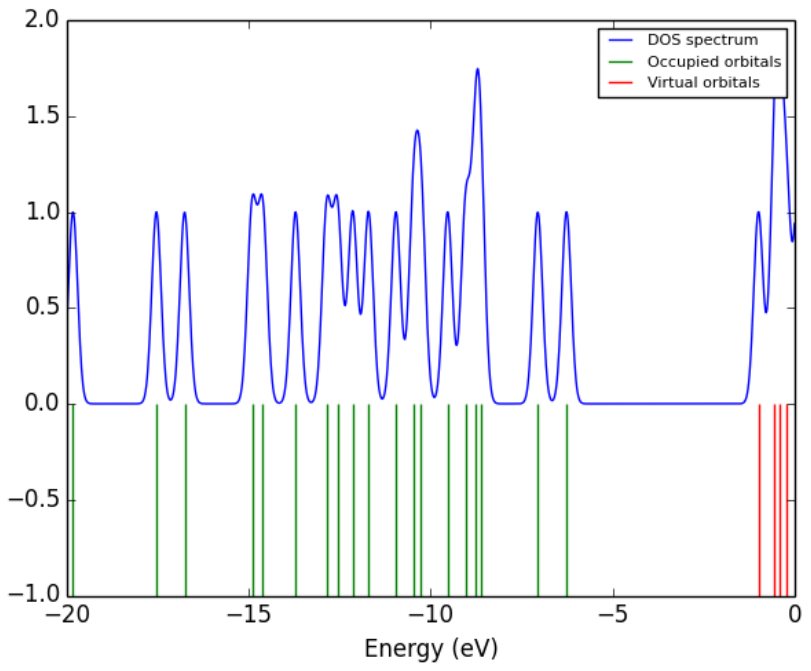

Fig.5 DOS Spectrum of 2,5 DCA

\subsection{Molecular Electrostatic Potential}


The molecular electrostatic potential (MEP) is a useful descriptor in understanding sites for electrophilic attack, nucleophilic attack and the hydrogen bonding interactions. The MEP of 2, 5 DCA is illustrated in Fig. 6. The molecular electrostatic potential is the potential energy of a proton at a particular position near a molecule. Negative electrostatic potential corresponds to a attraction of the proton by the concentrated electron density in the molecules (from lone pairs, pi-bonds, etc.). It is represented in shades of red colour. Positive electrostatic potential corresponds to repulsion of the proton by the atomic nuclei in regions where low electron density exists and it is colored in shades of blue. If the surface is largely white or lighter color shades, the molecule is mostly non-polar[44-46]. Also the 3D plots of total electron density, alpha density and electrostatic potential ESP is shown in Fig.6 In the color scheme for the MEP surface, red represents electron rich, partially negative charge: blue correspond to electron deficient, partially positive charge: light blue for slightly electron deficient region; yellow for slightly electron rich region; green for neutral, respectively. The electrostatic potential increases in the order as red $<$ orange $<$ yellow $<$ green $<$ blue. In the MEP map of the title molecule, the regions around the electronegative atoms $\mathrm{CC}$ group, chlorine and nitrogen atoms are represented as negative potential (red) and the regions hydrogen atoms are positive potential (blue). The $\mathrm{H}$ atoms indicate the strongest attraction and the $\mathrm{Cl}$ and $\mathrm{N}$ atoms indicates the strongest repulsion with other atoms.

\subsection{Thermodynamic Properties}

On the basis of vibrational analysis at G09 on B3LYP/-311G++(d,p) bsis set, the standard thermodynamic functions namely, heat capacity $(\mathrm{C})$, entropy $(\mathrm{S})$ and enthalpy changes $(\mathrm{H})$ for the 2,5 DCA were obtained and are listed in Table 5. The comparative graph of heat capacity (C), entropy (S) and enthalpy changes $(\mathrm{H})$ for 2,5 DCA was shown in Fig. 7. From Table 5, it can be observed that these thermodynamic functions are increasing with increase of temperature from 100 to $1000 \mathrm{~K}$, since the molecular vibrational intensities are increasing with temperature $[47,48]$. All these functions were calculated in gas phase and they could not be used in solution. Further, these thermodynamic data are providing supportive information for future study of 2,5 DCA and can be used to compute other thermodynamic energies according to the law of thermodynamics.

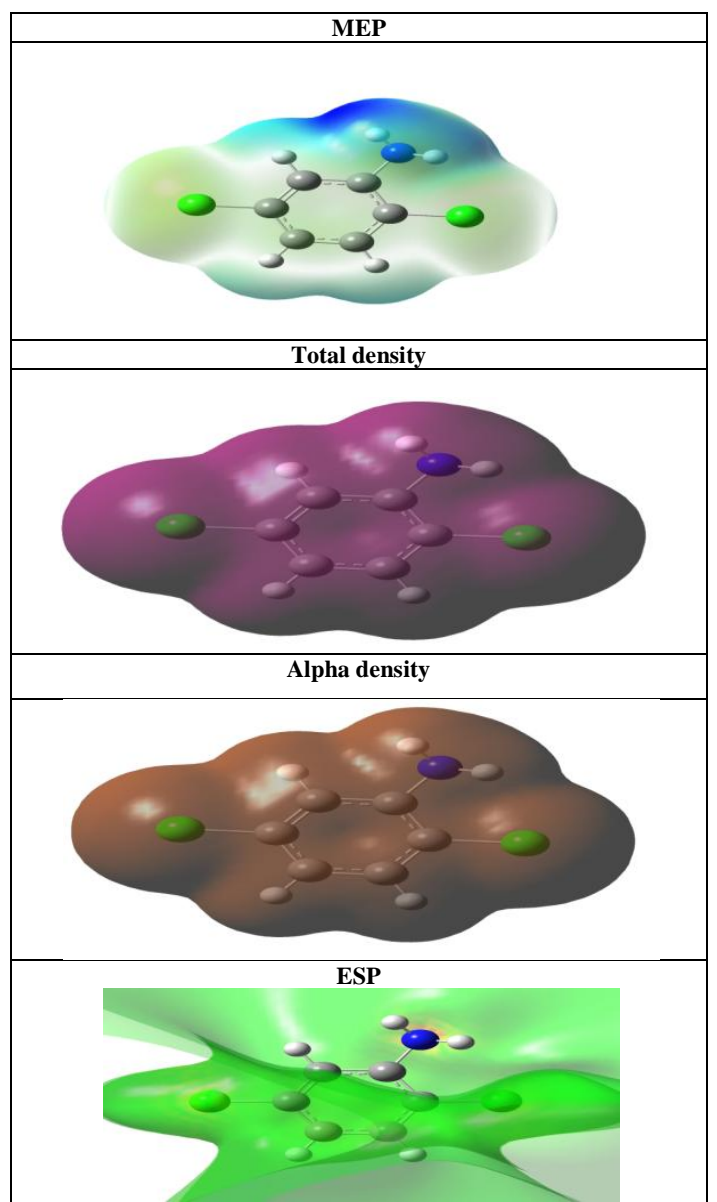

Fig.6 MEP, Total density, Alpha density and ESP of 2,5 DCA

Table 5 The specific heat capacity $\mathbf{C}$, entropy $\mathbf{S}$ and enthalpy changes $\Delta \mathbf{H}$ of 2,5 DCA

\begin{tabular}{|l|l|l|l|}
\hline $\mathbf{T}(\mathbf{K})$ & $\mathbf{C}\left(\mathrm{J} / \mathrm{mol}^{-1} \mathbf{K}^{-1}\right)$ & $\mathbf{S}\left(\mathrm{cal} \mathrm{mol}^{-1} \mathbf{K}^{-1}\right)$ & $\Delta \mathbf{H}\left(\mathrm{kcal} / \mathbf{m o l}^{-1}\right)$ \\
\hline
\end{tabular}




\begin{tabular}{|r|r|r|r|}
\hline 100 & 57.2 & 273.82 & 4.14 \\
\hline 200 & 97.06 & 325.85 & 11.87 \\
\hline 298.15 & 132.31 & 371.32 & 23.16 \\
\hline 300 & 132.93 & 372.14 & 23.41 \\
\hline 400 & 163.63 & 414.72 & 38.29 \\
\hline 500 & 188.51 & 454.01 & 55.94 \\
\hline 600 & 208.19 & 490.19 & 75.81 \\
\hline 700 & 223.84 & 523.51 & 97.45 \\
\hline 800 & 236.5 & 554.25 & 120.48 \\
\hline 900 & 246.96 & 582.73 & 144.67 \\
\hline
\end{tabular}

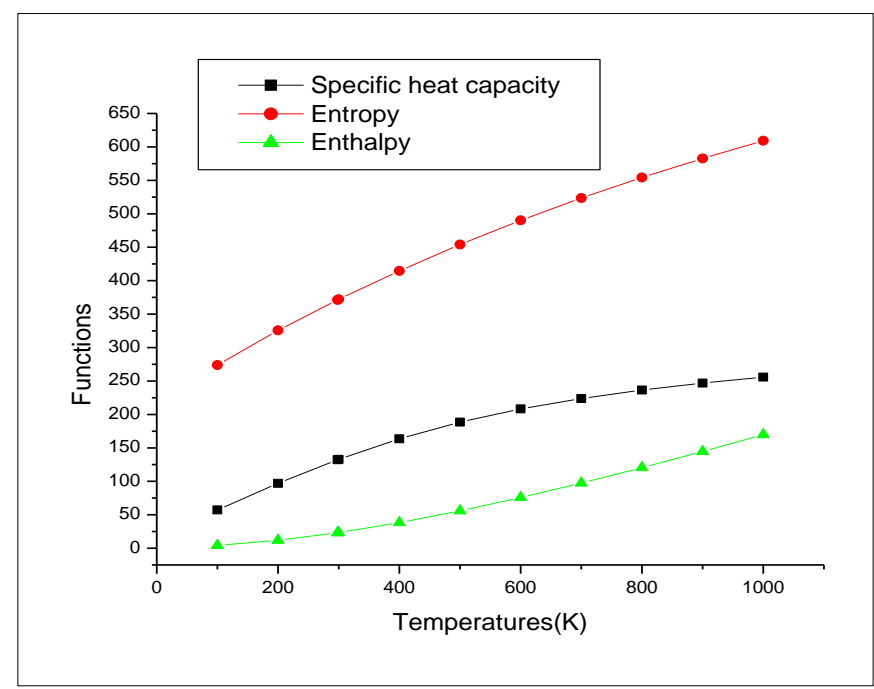

Fig.7 Comparative graph of Heat capacity, Entropy and Enthalpy of 2,5 DCA

\subsection{Atomic Charge}

In the application of quantum chemical calculation, the atomic charges play an important role, since atomic charges affect the dipole moment, molecular polarizability, electronic structure and a lot of electronic properties of systems. The atomic charges were calculated at HF and B3LYP/6-311++G(d,p) basis set level for comparison and are listed in Table 6 and the mulliken atomic charges plot for 2,5 DCA is plotted in Fig.8. This study shows that some carbon atoms have most positive and negative charges and hydrogen atoms all most positive charges. In this Table 6 , it is seen that the nitrogen atom has small negative charge for both basis sets. For the $\mathrm{HF}$ calculation, the $\mathrm{H}_{8}$ and $\mathrm{H}_{9}$ atoms shows the higher positive charge. The $\mathrm{C}_{1}, \mathrm{C}_{3} \mathrm{C}_{4}$ and $\mathrm{C}_{5}$ atoms have highest negative charges and $\mathrm{C}_{2}$ and $\mathrm{C}_{6}$ atoms have highest positive charge. The same result is obtained for B3LYP calculation except for $\mathrm{C}_{5}$ atom which is positive. From the calculated atomic charges of Aniline, the charge of $\mathrm{C} 1$ atom is $0.5452 \mathbf{e}^{-}$and that of the title molecule is $-0.93747 \mathbf{e}^{-}$[49]. The increase in negative charge is because of the presence of two chlorine atoms and $\mathrm{NH}_{2}$ group and thus it leads to the redistribution of electron density.

Table 6 Mulliken atomic charge of 2,5 DCA

\begin{tabular}{|c|c|c|}
\hline Atoms & HF/6-31+G(d,p) & B3LYP/6-311++G(d,p) \\
\hline C1 & -1.60976 & -0.93747 \\
\hline C2 & 1.200542 & 0.880028 \\
\hline C3 & -0.68905 & -0.65278 \\
\hline C4 5 & -0.2678 & -0.90584 \\
\hline C6 & -0.38884 & 0.637308 \\
\hline H7 & 0.701298 & -0.43742 \\
\hline H8 & 0.198935 & 0.193558 \\
\hline H9 & 0.19367 & 0.169707 \\
\hline CL10 & 0.186336 & 0.153688 \\
\hline CL1 & 0.183843 & 0.305828 \\
\hline N12 & 0.223058 & 0.332137 \\
\hline H13 & -0.5538 & -0.248 \\
\hline H14 & 0.296085 & 0.238284 \\
\hline & 0.325482 & 0.270978 \\
\hline
\end{tabular}




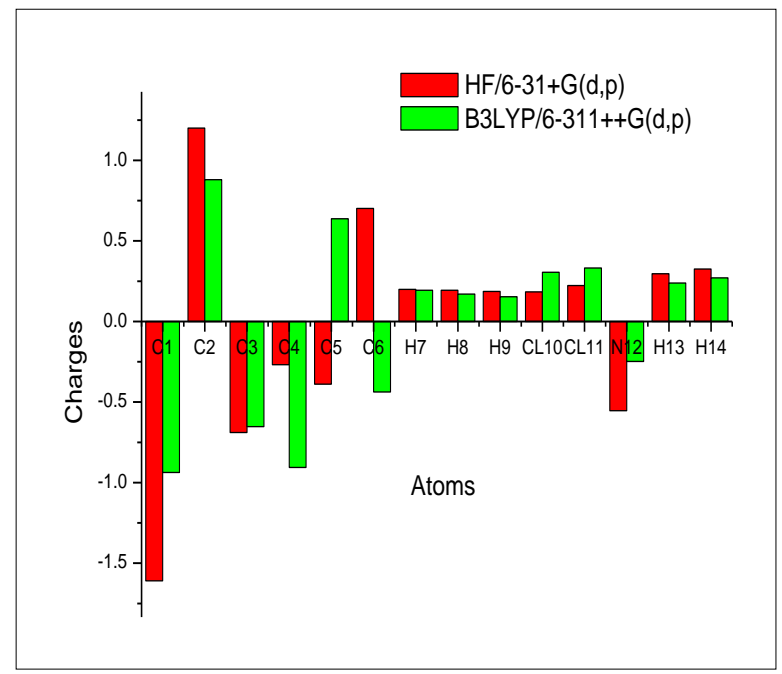

Fig.8 Mulliken atomic charge plot for 2,5 DCA

\subsection{NLO Properties}

The molecular electronic dipole moments $\mu$ (Debye), Polarizability $\left(\alpha_{0}\right)$ and first order hyperpolarizability $\left(\beta_{0}\right)$ values of 2,5 DCA calculated using B3LYP/with two different basis set was listed in Table 7. The first order hyperpolarizability is a tensor represented by $3 \mathrm{X} 3 \mathrm{X} 3$ matrix. The output from the above basis set provides 3 components of dipole moment namely $\mu \mathrm{x}, \mu \mathrm{y}, \mu \mathrm{z}, 6$ componenets of polarizability $\alpha$ and 10 components of hyperpolarizability $\beta$. From these values, the total dipole moment $\mu$, Polarizability $\left(\alpha_{0}\right)$ and hyperpolarizability $\left(\beta_{0}\right)$ values can be calculated using the following equations:

$$
\begin{array}{lc}
\mu=\left(\mu x^{2}+\mu y^{2}+\mu z^{2}\right)^{1 / 2} & (9) \\
\alpha_{0}=\alpha x x+\alpha y y+\alpha z z / 3 & (10) \\
\beta_{0}=\left(\beta x^{2}+\beta y^{2}+\beta z^{2}\right)^{1 / 2} & (11) \\
\text { Where, } & \\
\beta x= & \beta x x x+\beta x y y+\beta x z z \\
\beta y= & \beta y y y+\beta x x y+\beta y z z \\
\beta z= & \beta z z z+\beta x x z+\beta y y z
\end{array}
$$

The values of polarizability $\left(\alpha_{0}\right)$ and hyperpolarizability $\left(\beta_{0}\right)$ of B3LYP/6-31+G(d,p) and B3LYP/6$311++\mathrm{G}(\mathrm{d}, \mathrm{p})$ output are reported in atomic units (a.u), the values shown in table have been converted into electrostatic units (esu) (for $\alpha_{0} ; 1$ a.u $=0.1482 \times 10^{-24}$ esu, for $\beta_{0} ; 1$ a.u $=8.6393 \times 10^{-33}$ esu). The value of dipole moment $\mu$ was found to be 0.7923 Debye for B3LYP/6-31+G(d,p) basis set and 0.7028 Debye for B3LYP/6-311++G(d,p) level. The B3LYP/6-311++G(d,p) calculated polarizability $\alpha_{0}$ and first hyperpolarizability value $\beta_{0}$ of 2,5 -DCAwas found to be $0.2749 \times 10^{-30}$ esu and $2.3136 \times 10^{-30}$ esu respectively. But the HF/6-311G(d,p) calculated polarizability $\alpha_{0}$ and first hyperpolarizability value $\beta_{0}$ of 2,4,5-Trichloro Aniline was calculated as $0.4554 \times 10^{-30}$ esu and $1.118551 \mathrm{X}^{-30}$ esu respectively. The molecular dipole moment and first hyperpolarizability $\mu$ and $\beta_{0}$ of urea are 1.5285 Debye and $0.343272 \times 10^{-30}$ esu obtained by $\mathrm{HF} / 6-311 \mathrm{G}(\mathrm{d}, \mathrm{p})$ method. The magnitude of the molecular hyperpolarizability $\beta_{0}$, is one of important key factors in a NLO system. From these results, it is clear that the value of hyperpolarizability of the molecule under study is greater and this leading to more attractive molecule for future NLO studies.

Table 7 The molecular electric dipole moments $\mu$ (Debye), Polarizability $\left(\alpha_{0}\right)$ and hyperpolarizability $\left(\beta_{0}\right)$ values of 2,5 DCA.

\begin{tabular}{|c|c|c|}
\hline Parameters & B3LYP/6-31+G(d,p) & B3LYP/6-311++G(d,p) \\
\hline Dipole moment $(\boldsymbol{\mu})$ & & Debye \\
\hline$\mu_{\mathrm{x}}$ & 0.4559 & -0.5268 \\
\hline$\mu_{\mathrm{y}}$ & 0.6480 & -0.3488 \\
\hline$\mu_{\mathrm{z}}$ & 0.0 & -0.3077 \\
\hline $\boldsymbol{\mu}$ & 0.7923 & 0.7028 \\
\hline Polarizability $\left(\boldsymbol{\alpha}_{\mathbf{0}}\right)$ & & $\mathbf{x 1 0 ^ { - 3 0 }} \boldsymbol{e s u}^{108.0411}$ \\
\hline$\alpha_{\mathrm{xx}}$ & 146.6876 & 108.0 \\
\hline
\end{tabular}


Spectroscopic Investigation (FT-IR, FT-RAMAN, UV and NMR), NBO, NLO Analysis and Fukui

\begin{tabular}{|c|c|c|}
\hline$\alpha_{x y}$ & 4.0399 & 4.4505 \\
\hline$\alpha_{\mathrm{yy}}$ & 107.6582 & 14.3401 \\
\hline$\alpha_{x z}$ & 0 & -1.5806 \\
\hline$\alpha_{\mathrm{yz}}$ & 0 & 3.4990 \\
\hline$\alpha_{\mathrm{zz}}$ & 57.4581 & 58.5855 \\
\hline$\alpha_{0}$ & 0.2734 & 0.2749 \\
\hline \multicolumn{2}{|c|}{$\mathrm{x} 10^{-30} e s u$} & $\mathrm{x} 10^{-30} e s u$ \\
\hline$\beta_{\mathrm{xxx}}$ & 13.1078 & $143 . .31$ \\
\hline$\beta_{x x y}$ & -100.3905 & 153.3 \\
\hline$\beta_{x y y}$ & -176.4785 & 70.91 \\
\hline$\beta_{\mathrm{yyy}}$ & -185.2833 & -12.7882 \\
\hline$\beta_{\mathrm{xxz}}$ & 0 & -5.7418 \\
\hline$\beta_{\mathrm{xyz}}$ & 0 & -2.8146 \\
\hline$\beta_{\mathrm{yyz}}$ & 0 & -18.9268 \\
\hline$\beta_{\mathrm{xzz}}$ & 5.8398 & -0.7080 \\
\hline$\beta_{\mathrm{yzz}}$ & -5.0261 & 15.1391 \\
\hline$\beta_{\mathrm{zzz}}$ & 0 & -17.6982 \\
\hline $\boldsymbol{\beta}_{0}$ & 2.8564 & 2.3136 \\
\hline
\end{tabular}

Standard value for urea $\left(\boldsymbol{\mu}=1.3732\right.$ Debye, $\left.\boldsymbol{\beta}_{0}=0.3728 \times 10^{-30} \mathrm{esu}\right)$ : esu-electrostatic unit

\subsection{UV-Analysis}

The UV-Vis absorption spectrum of 2,5 DCA is recorded in the range 200-800 nm. Aniline has strong UV-Vis absorption at $232 \mathrm{~nm}$ and $285 \mathrm{~nm}$. The UV-Vis spectral analyses of the molecule have been investigated in Gas phase, Chloroform and DMSO by, TD-DFT/B3LYP/6-311++G(d,p) calculations. The electronic transitions and the corresponding excitation energies for the three phases are presented Table 8. It is obvious that, , the calculated absorption maxima values have been found to be 260, 236 and $223 \mathrm{~nm}$ for gas phase, 260, 236 and $223 \mathrm{~nm}$ for chloroform and 259, 235 and $222 \mathrm{~nm}$ for DMSO method. This shows that, the calculations performed at gas phase and chloroform is identical. The corresponding value for DMSO is closer to that of other two. Comparing the corresponding calculation of 2,4,5-Trichloro Aniline, this structure allow strong $\pi-\pi^{*}$ transition in the UV-Vis region with high oscillator strengths and low absorption wavelength for all the three phases. Thereby giving rise to significant electronic properties. The experimental UV-Vis absorption spectrums of 2,5 DCA was depicted Fig.9.

Table 8 The electronic transition of 2,5 DCA using DFT-B3LYP/6-311++G(d,p) basis set

In Gas phase.

\begin{tabular}{cccc}
\hline $\begin{array}{c}\text { Calculated at } \\
\text { B3lyp/6-311++g(d,p) }\end{array}$ & Oscillator strength & $\begin{array}{c}\text { Calculated } \\
\text { Band gap }(\mathbf{e v} / \mathbf{n m})\end{array}$ & $\begin{array}{c}\text { Experimental } \\
\text { Band of Aniline( nm) }\end{array}$ \\
\hline Excited State 1 & Singlet-A(f=0.0356) & $4.7590 \mathrm{eV} / 260.53 \mathrm{~nm}$ & \\
$40->42$ & 0.12603 & & 280 \\
$40->43$ & -0.28975 & & \\
$41->42$ & 0.61236 & & \\
$41->43$ & 0.12789 & & \\
\hline
\end{tabular}

\begin{tabular}{ccc} 
Excited State 2 & Singlet-A(f=0.0546) & $5.2491 \mathrm{eV} / 236.20 \mathrm{~nm}$ \\
$39 \rightarrow 43$ & 0.10589 & \\
$40 \rightarrow 42$ & 0.33050 & \\
$40 \rightarrow 43$ & 0.22142 & \\
$41 \rightarrow 43$ & 0.56164 & $5.5358 \mathrm{eV} / 223.97 \mathrm{~nm}$ \\
\hline Excited State 3 & Singlet- $\mathrm{A}(\mathrm{f}=0.1076)$ & \\
$39 \rightarrow 42$ & 0.34664 & \\
$40 \rightarrow 42$ & 0.44762 & \\
$40 \rightarrow 43$ & 0.21219 & \\
$41 \rightarrow 43$ & -0.32600 &
\end{tabular}

\begin{tabular}{|c|c|c|}
\hline \multicolumn{3}{|l|}{ In Chloroform } \\
\hline Excited State 1 & Singlet-A $(\mathrm{f}=0.0356)$ & $4.7590 \mathrm{eV} / 260.53 \mathrm{~nm}$ \\
\hline $40->42$ & 0.12603 & \\
\hline $40->43$ & -0.28975 & \\
\hline $41->42$ & 0.61236 & \\
\hline $41->43$ & 0.12789 & \\
\hline Excited State 2 & Singlet-A $(\mathrm{f}=0.0546)$ & $5.2491 \mathrm{eV} / 236.20 \mathrm{~nm}$ \\
\hline
\end{tabular}


Spectroscopic Investigation (FT-IR, FT-RAMAN, UV and NMR), NBO, NLO Analysis and Fukui

\begin{tabular}{|c|c|c|c|c|c|c|c|c|}
\hline Type & Donor NBO (i) & ED/e & Acceptor NBO (j) & $\begin{array}{l}\mathrm{ED} / \mathrm{e} \\
\mathrm{KJ} / \mathrm{mol}\end{array}$ & $\begin{array}{l}\mathrm{E}(2) \\
\mathrm{KJ} / \mathrm{mol}\end{array}$ & $\begin{array}{l}\mathrm{E}(2) \\
\mathrm{Kcal} / \mathrm{mol}\end{array}$ & $\begin{array}{l}\text { E(j)-E(i) } \\
\text { a.u } \\
\end{array}$ & $\begin{array}{l}\mathrm{F}(\mathrm{I}, \mathrm{j}) \\
\text { a.u }\end{array}$ \\
\hline \multirow[t]{4}{*}{$\sigma-\sigma^{*}$} & $\begin{array}{l}\mathrm{BD}(1) \mathrm{C} 1-\mathrm{C} \\
2\end{array}$ & 1.97803 & $\mathrm{BD}^{*}\left(\begin{array}{llll}1) \mathrm{C} & 1-\mathrm{C} & 6\end{array}\right.$ & 0.02637 & 10.88 & 2.6 & 1.28 & 0.052 \\
\hline & & & $\mathrm{BD}^{*}(1) \mathrm{C} 2-\mathrm{C} 3$ & 0.02394 & 12.51 & 2.99 & 1.27 & 0.055 \\
\hline & & & $\mathrm{BD}^{*}\left(\begin{array}{lll}1) \mathrm{C} & 3-\mathrm{H} & 7\end{array}\right.$ & 0.01076 & 7.99 & 1.91 & 1.22 & 0.043 \\
\hline & & & $\begin{array}{llll}\mathrm{BD}^{*}( & 1) \mathrm{C} & 6-\mathrm{H} & 9\end{array}$ & 0.01156 & 7.15 & 1.71 & 1.21 & 0.041 \\
\hline \multirow[t]{3}{*}{$\pi-\pi^{*}$} & $\begin{array}{l}\mathrm{BD}(2) \mathrm{C} 1-\mathrm{C} \\
2\end{array}$ & 1.66178 & $\mathrm{BD}^{*}(2) \mathrm{C} \quad 3-\mathrm{C} 4$ & 0.32881 & 85.31 & 20.39 & 0.29 & 0.069 \\
\hline & & & BD*( 2) C $5-\mathrm{C} 6$ & 0.39903 & 78.87 & 18.85 & 0.28 & 0.065 \\
\hline & & & BD*( 1) N 12 - H 14 & 0.00639 & 6.69 & 1.6 & 0.77 & 0.034 \\
\hline \multirow[t]{5}{*}{$\sigma-\sigma^{*}$} & $\begin{array}{l}\mathrm{BD}(1) \mathrm{C} 1-\mathrm{C} \\
6\end{array}$ & 1.96662 & $\mathrm{BD}^{*}(1) \mathrm{C} 1-\mathrm{C} 2$ & 0.03925 & 14.77 & 3.53 & 1.26 & 0.06 \\
\hline & & & 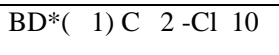 & 0.0274 & 17.7 & 4.23 & 0.86 & 0.054 \\
\hline & & & $\mathrm{BD}^{*}(1) \mathrm{C} \quad 5-\mathrm{C} 6$ & 0.02705 & 11.51 & 2.75 & 1.25 & 0.053 \\
\hline & & & BD*( 1) C $5-\mathrm{Cl} 11$ & 0.02897 & 18.28 & 4.37 & 0.85 & 0.054 \\
\hline & & & $\mathrm{BD}^{*}\left(\begin{array}{lll}1) \mathrm{C} & 6-\mathrm{H} & 9\end{array}\right.$ & 0.01156 & 5.02 & 1.2 & 1.19 & 0.034 \\
\hline \multirow[t]{2}{*}{$\sigma-\sigma^{*}$} & $\begin{array}{l}\mathrm{BD}(1) \mathrm{C} 1-\mathrm{N} \\
12\end{array}$ & 1.9897 & $\mathrm{BD} *(1) \mathrm{C} 2-\mathrm{C} 3$ & 0.02394 & 8.41 & 2.01 & 1.26 & 0.045 \\
\hline & & & $\mathrm{BD}^{*}(1) \mathrm{C} \quad 5-\mathrm{C} 6$ & 0.02705 & 7.61 & 1.82 & 1.26 & 0.043 \\
\hline \multirow[t]{5}{*}{$\sigma-\sigma^{*}$} & $\begin{array}{l}\mathrm{BD}(1) \mathrm{C} 2-\mathrm{C} \\
3\end{array}$ & 1.98002 & $\mathrm{BD}^{*}(1) \mathrm{C} 1-\mathrm{C} 2$ & 0.03925 & 13.97 & 3.34 & 1.27 & 0.058 \\
\hline & & & $\mathrm{BD}^{*}(1) \mathrm{C} 1-\mathrm{N} 12$ & 0.01705 & 15.94 & 3.81 & 1.07 & 0.057 \\
\hline & & & $\mathrm{BD}^{*}(1) \mathrm{C} \quad 3-\mathrm{C} 4$ & 0.01588 & 8.33 & 1.99 & 1.28 & 0.045 \\
\hline & & & $\mathrm{BD}^{*}\left(\begin{array}{llll}1) \mathrm{C} & 3-\mathrm{H} & 7\end{array}\right.$ & 0.01076 & 5.48 & 1.31 & 1.21 & 0.036 \\
\hline & & & BD*( 1) C $4-\mathrm{H} 8$ & 0.01119 & 7.99 & 1.91 & 1.21 & 0.043 \\
\hline \multirow[t]{2}{*}{$\sigma-\sigma^{*}$} & $\begin{array}{l}\mathrm{BD}(1) \mathrm{C} 2-\mathrm{Cl} \\
10\end{array}$ & 1.98907 & $\mathrm{BD}^{*}(1) \mathrm{C} \quad 1-\mathrm{C} 6$ & 0.02637 & 11.25 & 2.69 & 1.25 & 0.052 \\
\hline & & & $\mathrm{BD}^{*}(1) \mathrm{C} \quad 3-\mathrm{C} 4$ & 0.01588 & 9.33 & 2.23 & 1.26 & 0.047 \\
\hline \multirow[t]{6}{*}{$\sigma-\sigma^{*}$} & $\begin{array}{l}\mathrm{BD}(1) \mathrm{C} 3-\mathrm{C} \\
4\end{array}$ & 1.96639 & $\mathrm{BD}^{*}(1) \mathrm{C} 2-\mathrm{C} 3$ & 0.02394 & 10.29 & 2.46 & 1.24 & 0.049 \\
\hline & & & BD*( 1) C 2 -Cl 10 & 0.0274 & 19.33 & 4.62 & 0.84 & 0.056 \\
\hline & & & BD*( 1) C $3-\mathrm{H} 7$ & 0.01076 & 4.9 & 1.17 & 1.19 & 0.034 \\
\hline & & & $\mathrm{BD}^{*}(1) \mathrm{C} 4-\mathrm{C} 5$ & 0.02611 & 10.54 & 2.52 & 1.24 & 0.05 \\
\hline & & & $\mathrm{BD}^{*}(1) \mathrm{C} \quad 4-\mathrm{H} \quad 8$ & 0.01119 & 4.94 & 1.18 & 1.19 & 0.034 \\
\hline & & & BD*( 1) C 5 -Cl 11 & 0.02897 & 19.37 & 4.63 & 0.84 & 0.056 \\
\hline \multirow[t]{2}{*}{$\pi-\pi^{*}$} & $\begin{array}{l}\mathrm{BD}(2) \mathrm{C} 3-\mathrm{C} \\
4\end{array}$ & 1.67638 & $\mathrm{BD}^{*}(2) \mathrm{C} \quad 1-\mathrm{C} \quad 2$ & 0.41251 & 76.19 & 18.21 & 0.27 & 0.064 \\
\hline & & & $\mathrm{BD}^{*}(2) \mathrm{C} 5-\mathrm{C} 6$ & 0.39903 & 85.02 & 20.32 & 0.26 & 0.066 \\
\hline \multirow[t]{4}{*}{$\sigma-\sigma^{*}$} & $\begin{array}{l}\text { BD (1) C } 3-\mathrm{H} \\
7\end{array}$ & 1.97992 & $\mathrm{BD}^{*}(1) \mathrm{C} 1-\mathrm{C} 2$ & 0.03925 & 15.4 & 3.68 & 1.08 & 0.057 \\
\hline & & & $\mathrm{BD}^{*}(1) \mathrm{C} \quad 2-\mathrm{C} 3$ & 0.02394 & 4.31 & 1.03 & 1.08 & 0.03 \\
\hline & & & $\mathrm{BD}^{*}(1) \mathrm{C} \quad 3-\mathrm{C} 4$ & 0.01588 & 4.23 & 1.01 & 1.1 & 0.03 \\
\hline & & & BD*( 1)C 4-C 5 & 0.02611 & 14.52 & 3.47 & 1.08 & 0.055 \\
\hline \multirow[t]{5}{*}{$\sigma-\sigma^{*}$} & $\mathrm{BD}(1) \mathrm{C} 4$ - $\mathrm{C} 5$ & 1.98185 & $\mathrm{BD}^{*}(1) \mathrm{C} 3-\mathrm{C} 4$ & 0.01588 & 8.28 & 1.98 & 1.28 & 0.045 \\
\hline & & & $\mathrm{BD}^{*}(1) \mathrm{C} \quad 3-\mathrm{H} \quad 7$ & 0.01076 & 7.82 & 1.87 & 1.21 & 0.043 \\
\hline & & & BD*( 1) C $4-\mathrm{H} 8$ & 0.01119 & 5.56 & 1.33 & 1.21 & 0.036 \\
\hline & & & $\mathrm{BD}^{*}(1) \mathrm{C} \quad 5-\mathrm{C} 6$ & 0.02705 & 12.84 & 3.07 & 1.26 & 0.056 \\
\hline & & & $\mathrm{BD}^{*}\left(\begin{array}{lll}1) \mathrm{C} & 6-\mathrm{H} & 9\end{array}\right.$ & 0.01156 & 9.29 & 2.22 & 1.2 & 0.046 \\
\hline \multirow[t]{3}{*}{$\sigma-\sigma^{*}$} & $\mathrm{BD}(1) \mathrm{C} 4-\mathrm{H} 8$ & 1.98022 & $\mathrm{BD}^{*}(1) \mathrm{C} 2-\mathrm{C} 3$ & 0.02394 & 14.02 & 3.35 & 1.08 & 0.054 \\
\hline & & & BD*( 1) C $3-\mathrm{C} 4$ & 0.01588 & 4.18 & 1 & 1.09 & 0.03 \\
\hline & & & $\mathrm{BD}^{*}(1) \mathrm{C} 4-\mathrm{C} 5$ & 0.02611 & 4.27 & 1.02 & 1.08 & 0.03 \\
\hline
\end{tabular}


Spectroscopic Investigation (FT-IR, FT-RAMAN, UV and NMR), NBO, NLO Analysis and Fukui

\begin{tabular}{|c|c|c|c|c|c|c|c|c|}
\hline & & & BD*( 1) C 5 - C 6 & 0.02705 & 16.11 & 3.85 & 1.08 & 0.058 \\
\hline \multirow[t]{5}{*}{$\sigma-\sigma^{*}$} & $\begin{array}{l}\mathrm{BD}(1) \mathrm{C} 5-\mathrm{C} \\
6\end{array}$ & 1.97921 & BD*( 1) C 1 -C 6 & 0.02637 & 9.41 & 2.25 & 1.28 & 0.048 \\
\hline & & & BD*( 1) C $1-\mathrm{N} 12$ & 0.01705 & 14.69 & 3.51 & 1.07 & 0.055 \\
\hline & & & $\mathrm{BD}^{*}($ 1) C $4-\mathrm{C} 5$ & 0.02611 & 12.84 & 3.07 & 1.26 & 0.056 \\
\hline & & & $\mathrm{BD}^{*(}(1) \mathrm{C} \quad 4-\mathrm{H} 8$ & 0.01119 & 8.95 & 2.14 & 1.21 & 0.046 \\
\hline & & & $\mathrm{BD}^{*}(1) \mathrm{C} \quad 6-\mathrm{H} 9$ & 0.01156 & 6.4 & 1.53 & 1.2 & 0.038 \\
\hline \multirow[t]{2}{*}{$\pi-\pi^{*}$} & $\begin{array}{l}\mathrm{BD}(2) \mathrm{C} 5-\mathrm{C} \\
6\end{array}$ & 1.69118 & $\mathrm{BD}^{*}($ 2) C $1-\mathrm{C} 2$ & 0.41251 & 85.35 & 20.4 & 0.28 & 0.069 \\
\hline & & & $\mathrm{BD}^{*}($ 2) C $3-\mathrm{C} 4$ & 0.32881 & 76.4 & 18.26 & 0.29 & 0.065 \\
\hline \multirow[t]{2}{*}{$\sigma-\sigma^{*}$} & $\begin{array}{l}\mathrm{BD}(1) \mathrm{C} 5-\mathrm{Cl} \\
11\end{array}$ & 1.99072 & $\mathrm{BD}^{*}(1) \mathrm{C} \quad 1-\mathrm{C} 6$ & 0.02637 & 8.2 & 1.96 & 1.26 & 0.045 \\
\hline & & & BD*( 1) C $3-\mathrm{C}^{4} 4$ & 0.01588 & 9.16 & 2.19 & 1.27 & 0.047 \\
\hline \multirow[t]{4}{*}{$\sigma-\sigma^{*}$} & $\begin{array}{l}\mathrm{BD}(1) \mathrm{C} \quad 6-\mathrm{H} \\
9\end{array}$ & 1.97846 & $\mathrm{BD}^{*}(1) \mathrm{C} 1-\mathrm{C} 2$ & 0.03925 & 17.15 & 4.1 & 1.09 & 0.06 \\
\hline & & & $\mathrm{BD}^{*}(1) \mathrm{C} 1-\mathrm{C} 6$ & 0.02637 & 5.15 & 1.23 & 1.1 & 0.033 \\
\hline & & & $\mathrm{BD}^{*}(1) \mathrm{C} 4-\mathrm{C} 5$ & 0.02611 & 15.73 & 3.76 & 1.08 & 0.057 \\
\hline & & & $\mathrm{BD}^{*}(1) \mathrm{C} \quad 5-\mathrm{C} 6$ & 0.02705 & 4.77 & 1.14 & 1.08 & 0.031 \\
\hline \multirow[t]{2}{*}{$\overline{\sigma-\sigma^{*}}$} & $\mathrm{BD}(1) \mathrm{N} 12-\mathrm{H} 13$ & 1.98901 & $\mathrm{BD}^{*}(1) \mathrm{C} 1-\mathrm{C} 2$ & 0.03925 & 13.43 & 3.21 & 1.18 & 0.055 \\
\hline & & & BD*( 2) C $1-\mathrm{C} 2$ & 0.41251 & 4.69 & 1.12 & 0.64 & 0.027 \\
\hline$\sigma-\pi^{*}$ & $\mathrm{BD}($ ) $\mathrm{N} 12-\mathrm{H} 14$ & 1.97923 & $\mathrm{BD}^{*}(2) \mathrm{C} 1-\mathrm{C} 2$ & 0.41251 & 15.69 & 3.75 & 0.64 & 0.049 \\
\hline \multirow[t]{2}{*}{$\mathrm{n}-\sigma^{*}$} & $\mathrm{LP}(1) \mathrm{Cl} 10$ & 1.99329 & $\mathrm{BD}^{*}(1) \mathrm{C} 1-\mathrm{C} 2$ & 0.03925 & 4.27 & 1.02 & 1.46 & 0.035 \\
\hline & & & $\mathrm{BD}^{*}(1) \mathrm{C} 2-\mathrm{C} 3$ & 0.02394 & 7.15 & 1.71 & 1.46 & 0.045 \\
\hline \multirow[t]{2}{*}{$\mathrm{n}-\sigma^{*}$} & $\mathrm{LP}(2) \mathrm{Cl} 10$ & 1.96999 & BD*( 1) C $1-\mathrm{C} 2$ & 0.03925 & 19.71 & 4.71 & 0.85 & 0.057 \\
\hline & & & BD*( 1) C 2 - C 3 & 0.02394 & 14.9 & 3.56 & 0.85 & 0.049 \\
\hline $\mathrm{n}-\pi^{*}$ & $\mathrm{LP}(3) \mathrm{Cl} 10$ & 1.92829 & $\mathrm{BD}^{*}(2) \mathrm{C} \quad 1-\mathrm{C} \quad 2$ & 0.41251 & 52.05 & 12.44 & 0.32 & 0.061 \\
\hline \multirow[t]{2}{*}{$n-\sigma^{*}$} & $\mathrm{LP}(1) \mathrm{Cl} 11$ & 1.99236 & BD*( 1)C $4-\mathrm{C} 5$ & 0.02611 & 6.86 & 1.64 & 1.46 & 0.044 \\
\hline & & & BD*( 1) C 5 -C 6 & 0.02705 & 6.49 & 1.55 & 1.47 & 0.043 \\
\hline \multirow[t]{2}{*}{$\mathrm{n}-\sigma^{*}$} & $\mathrm{LP}(2) \mathrm{Cl} 11$ & 1.97179 & BD*( 1)C $4-\mathrm{C} 5$ & 0.02611 & 16.74 & 4 & 0.86 & 0.052 \\
\hline & & & $\mathrm{BD}^{*}($ 1) C $5-\mathrm{C} 6$ & 0.02705 & 16.9 & 4.04 & 0.86 & 0.053 \\
\hline $\mathrm{n}-\pi^{*}$ & $\mathrm{LP}(3) \mathrm{Cl} 11$ & 1.93117 & BD*( 2) C 5 -C 6 & 0.39903 & 51.92 & 12.41 & 0.32 & 0.062 \\
\hline \multirow[t]{3}{*}{$\mathrm{n}-\sigma^{*}$} & LP ( 1) N 12 & 1.93802 & $\mathrm{BD}^{*}(1) \mathrm{C} 1-\mathrm{C} 2$ & 0.03925 & 9.04 & 2.16 & 0.85 & 0.039 \\
\hline & & & $\mathrm{BD}^{*}($ 2) C $1-\mathrm{C} 2$ & 0.41251 & 18.45 & 4.41 & 0.32 & 0.037 \\
\hline & & & BD*( 1) C 1 -C 6 & 0.02637 & 25.82 & 6.17 & 0.86 & 0.066 \\
\hline$\pi^{*}-\pi^{*}$ & $\begin{array}{l}\text { BD*( 2) C } 1-\mathrm{C} \\
2\end{array}$ & 0.41251 & BD*( 2) C $3-\mathrm{C}_{4} 4$ & 0.32881 & 1023.62 & 244.65 & 0.01 & 0.078 \\
\hline$\pi^{*}-\pi^{*}$ & $\begin{array}{l}\text { BD*( 2) C } 5-\mathrm{C} \\
6\end{array}$ & 0.39903 & 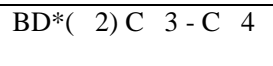 & 0.32881 & 763.08 & 182.38 & 0.02 & 0.079 \\
\hline
\end{tabular}

The strong intramolecular interaction are formed by the orbital overlap between $\sigma(\mathrm{C}-\mathrm{C}), \sigma^{*}(\mathrm{C}-\mathrm{C}), \sigma$ $(\mathrm{C}-\mathrm{N}), \sigma^{*}(\mathrm{C}-\mathrm{N}), \sigma(\mathrm{C}-\mathrm{Cl}), \sigma^{*}(\mathrm{C}-\mathrm{Cl})$ and $\pi(\mathrm{C}-\mathrm{C}), \pi^{*}(\mathrm{C}-\mathrm{C})$ bond orbitals. This leads to intramolecular charge transfer (ICT) and thereby causing stabilization of the system. These intramolecular charge transfer $\left(\sigma \rightarrow \sigma^{*}, \pi\right.$ $\rightarrow \pi^{*}$ ) will cause large nonlinearity of the molecule. The strong intramolecular hyper conjugation interaction of the $\sigma$ and $\pi$ electrons of C-C and C-N to the anti C-C, C-H, C-N and N-H bonds, give rise to the stabilization of some part of the ring as evident from Table 9. The interaction of the $\sigma$ electron of $(\mathrm{C} 1-\mathrm{C} 6)$ distribute to $\sigma^{*}(\mathrm{C} 1-$ $\mathrm{C} 2$ ), (C2-CL10), (C5-C6), ( C5-CL11 )and (C6-H9) of the ring. Also, the $\pi$ bond of $\mathrm{C} 1-\mathrm{C} 2$ in the ring transfers energy of $85.32 \mathrm{KJ} / \mathrm{mol}$ to the antibonding orbital of the $\pi^{*}(\mathrm{C} 3-\mathrm{C} 4)$ and an energy of $78.87 \mathrm{KJ} / \mathrm{mol}$ to the antibonding orbital $\pi^{*}(\mathrm{C} 5-\mathrm{C} 6)$. The intra-molecular interaction is formed due to the orbital overlap of $\pi$ (C5C6) with $\pi^{*}(\mathrm{C} 1-\mathrm{C} 2) \pi^{*}(\mathrm{C} 3-\mathrm{C} 4)$ with energy of 85.35 and $76.4 \mathrm{KJ} / \mathrm{mol}$ respectively. Also the $\pi$ (C3-C4) interacts with $\pi^{*}(\mathrm{C} 1-\mathrm{C} 2)$ and $\pi^{*}(\mathrm{C} 5-\mathrm{C} 6)$ with energies of 76.19 and $85.02 \mathrm{KJ} / \mathrm{mole}$ respectively. Apart from $\pi-\pi^{*}, \sigma-\sigma^{*}$ and $\pi^{*}-\pi^{*}$ interactions, $\mathrm{n}-\sigma^{*}, \mathrm{n}-\pi^{*}$ and $\sigma-\pi^{*}$ interactions also occur in the hyper conjugative interactions of 2,5 DCA. There by predicting the charge transfer between lone pair bonds and acceptor bonds with in the molecule. 
The more energy transfer takes place during $\pi$ to $\pi^{*}$ transition rather than $\sigma$ to $\sigma^{*}$. The maximum stabilization energy $\mathrm{E}(2)$ associated with hyper conjugative interaction $\pi\left(\mathrm{C}_{5}-\mathrm{C}_{6}\right) \rightarrow \pi^{*}\left(\mathrm{C}_{1}-\mathrm{C}_{2}\right)$ is obtained as $85.35 \mathrm{KJ} / \mathrm{mol}$, which is due to two chlorine atoms attached with $\mathrm{C}_{2}$ and $\mathrm{C}_{5}$ atoms.

\subsection{NMR Spectra Analysis}

NMR analysis is used to elucidate the molecular structure and the types of atoms in a sample. It is also used to predict details about the composition of atoms and chemical environment of atoms in the molecule. In nuclear magnetic resonance (NMR), the chemical shift is the resonant frequency of a nucleus from that of a standard molecule with application of a magnetic field. The ${ }^{1} \mathrm{H}$ and ${ }^{13} \mathrm{C}$ NMR chemical shifts calculated by applying B3LYP /6-311++G (d,p) levels was summarized in Table 10. The ${ }^{1} \mathrm{H}$ and ${ }^{13} \mathrm{C}$ experimental shifts in ppm for the molecule 2,5 DCA are also given. The ${ }^{13} \mathrm{C}$ chemical shift values of all $\mathrm{C}$ atoms lie in the range $116.84-148.937 \mathrm{ppm}$ for the compound . For all aromatic carbons, the ${ }^{13} \mathrm{C}$ chemical shift values are in the range $100-150 \mathrm{ppm}$.[49] The ${ }^{1} \mathrm{H}$ chemical shift values of all $\mathrm{H}$ atoms have the range $2.98-6.96 \mathrm{ppm}$. From Table 10, it was found that the theoretical ${ }^{1} \mathrm{H}$ and ${ }^{13} \mathrm{C}$ chemical shift results of 2,5 DCA are higher than that of the experimental data of 2,4,5-TrichloroAniline molecule. This shows that the atoms are more deshielded by their electrons.That is, the electron density decreases due to the presence of electronegative atoms $\mathrm{N}$ and $\mathrm{Cl}$. Thus the nucleus experiences high external field and a high frequency to achieve resonance and therefore shifing to higher ppm. It is also found that the $\mathrm{H} 13$ and $\mathrm{H} 14$ atoms experience lower external field and thus low frequency to achieve resonance. This is called shielding and the corresponding shift decreases.

Table 10. Theoretical and experimental ${ }^{1} \mathrm{H}$ and ${ }^{13} \mathrm{C}$ chemical shift (ppm) of 2,5 DCA

\begin{tabular}{|c|c|l|l|}
\hline Atoms & $\begin{array}{c}\text { Isotropic chemical shielding } \\
\text { tensor }(\boldsymbol{\sigma}) \mathbf{( p p m )}\end{array}$ & Theoretical Shift (ppm) & $*$ Experimental Shift(ppm) \\
\hline C1 & 33.5760 & 148.937 & 142.51 \\
\hline C2 & 55.3448 & 127.165 & 116.20 \\
\hline C3 & 48.3361 & 134.228 & 131.29 \\
\hline C4 & 61.5184 & 120.958 & 120.88 \\
\hline C5 & 36.0018 & 146.476 & 130.12 \\
\hline C6 & 65.7184 & 116.84 & 117.92 \\
\hline H7 & 24.9226 & 6.96 & 6.96 \\
\hline H8 & 25.4647 & 6.418 & 6.57 \\
\hline H9 & 25.4410 & 6.440 & 6.41 \\
\hline H13 & 28.8851 & 2.98 & 4.0 \\
\hline H14 & 28.2974 & 3.58 & 4.0 \\
\hline
\end{tabular}

*The experimental ${ }^{1} \mathrm{H}$ and ${ }^{13} \mathrm{Cchemical}$ shift of 2,4,5-Trichloro Aniline

\section{Conclusions}

The detailed spectral investigation of the molecule 2,5 DCA have been carried out and interpreted. The optimized structural parameters were calculated using HF/B3LYP method with $6-31+\mathrm{G}(\mathrm{d}, \mathrm{p})$ and $6-311++\mathrm{G}(\mathrm{d}$, p) basis sets. The calculated bond parameters were found to agree with the literature XRD data of Aniline and Nitro Aniline. From the order of bond length, it is noted that the benzene ring is little distorted from perfect hexagonal structure, which is naturally because of the substitutions of $\mathrm{NH}_{2}$ group and chlorine $(\mathrm{Cl})$ atom in the place of $\mathrm{H}$ atoms in the $\mathrm{C}-\mathrm{C}$ ring. The extension of bond length in the $\mathrm{C}-\mathrm{Cl}$ bond is found greater than that in $\mathrm{C}$ $\mathrm{N}$ bond. The result obtained from the TED analysis clearly explains the vibrational assignment of all functional groups and also the influence of $\mathrm{C}-\mathrm{Cl}$, the $\mathrm{NH}_{2}$ group on the benzene ring were discussed. Therefore, it was found that these assignments showed small deviations from the experimental values.

Investigations throughout the work prove that the NLO, HOMO-LUMO energy analysis, MEP, Mulliken charges and all other, molecular parameters of the molecule 2,5 DCA can be successfully predicted by DFT method .The HOMO-LUMO energy gap indicates the stability and reactive site of the title molecule. The excellent agreement between the UV-Vis, absorption maxima and calculated electronic absorption maxima are found. The donor-acceptor interaction, as obtained from NBO analysis could fairly explains the decreases of occupancies of $\sigma$ bonding orbital and the increases of occupancy of $\pi^{*}$ antibonding orbital's. The visual display of FMOs, ESP, ED, MEP examined, discusses the charge distribution and interaction within the molecule.

To sum up, the negative region (red) is mainly over the $\mathrm{N}$ and $\mathrm{Cl}$ atomic sites, which were caused by the contribution of lone-pair electrons of nitrogen and chlorine atom while the positive (blue) potential sites are around the hydrogen atoms. The MEP study is confirmed with the findings of the local reactivity and Fukui indices. Also, the value of hyperpolarizability of the molecule under study is greater and thus giving rise to more attractive NLO properties for future studies. The NMR study clearly explains how a particular atomic nucleus respond to the application of external magnetic field and able to predict the nature and characteristics of atoms present in the molecule. From the literature study of related molecules, it was found that the chemical shift data of 2,5 DCA are more than that of Aniline. 


\section{References}

[1] J. Whysner, L. Vera, G.M.Williams, Pharmacol. Ther. 71 (1996) 107.

[2] A. Altun, K. GOlc “u’k, M. Kumru, J. Mol. Struct. (Theochem.) 625 (2003) 17.

[3] N. Sundaraganesana, J. Karpagama, S. Sebastiana, J.P. Cornard, Spectrochimica Acta Part A 73 (2009) 11-19.

[4] Amareshwar Kumar Raia, Sanjay Kumarb, Anita Raic, Vibrational Spectroscopy, 42 ( 2006) $397-402$.

[5] Mehmet Karabacak, Mustafa Kurt, Ahmet Ataç, Journal of Physical Organic Chemistry, 22 (2009) $321-330$.

[6] Halina Szatyłowicz, Tadeusz M. Krygowski, Pavel Hobza, Journal of Physical Organic Chemistry A, 111( 2007) 170-175.

[7] M. Kurta, M. Yurdakulb, Ş. Yurdakula, Journal of Molecular Structure THEOCHEM711( 2004) 25-32.

[8] V.Arjunana and S.Mohan, Spectrochimica Acta Part A,72( 2009) 436-444.

[9] M.H. Jamróz, Vibrational Energy Distribution Analysis VEDA 4, Warsaw, 2004.

[10] A. Frisch, A.B. Nielson, A.J. Holder, GAUSSVIEW User Manual, Gaussian Inc., (Pittsburgh, PA, 2000).

[11] M.K. Ahmed, B.R. Henry, J. Phys. Chem. 90 (1986) 1737.

[12] J.V. Prasad, S.B. Rai, S.N. Thakur, Chem. Phys. Lett. 164 (6) (1989) 629.

[13] G.D. Lister, J.K. Tyler, J.H. Hog, N.W. Larsen, J. Mol. Struct. 23 (1974) 253.

[14] J.R. Durig, T.S. Little, T.K. Gounev, J.K. Gargner Jr., J.F. Sullivan, J. Mol. Struct. 375 (1996) 83.

[15] V. Krishnakumar, V. Balachandran, T. Chithambarathann, Spectrochimica Acta part A 62 (2005) 918-925.

[16] W.O. George and P.S. Mcintyre, Infrared Spectroscopy, (John Wiley \& Sons, London, 1987).

[17] J. Coates, R.A. Meyers, Interpretation of Infrared Spectra: A Practical Approach,(John Wiley and Sons Ltd., Chichester, 2000).

[18] V. Krishna kumar, N. Prabavathi, Spectrochimica Acta part A 71 (2008) 449-457.

[19] A. Altun, K. Golcuk, M. Kumru, Journal of Molecular structure (Theochem.) 155. (2003)637-639.

[20] V. Krishna kumar, R. John Xavier, Spectrochimica Acta part A 61 (2005) 253-258.

[21] S. George, Infrared and Raman Characteristic Group Frequencies-Tables and Charts, third ed., (Wiley, New York, 2001).

[22] A. R. Prabakaran and S. Mohan, Indian Journal of Physics, vol.63B, (1989) 468-473.

[23] G. Varsanyi, Assignments of Vibrational Spectra of 700 Benzene Derivatives,(Wiley, New York, 1974).

[24] S.J.Singh, S.M.Pandey, J. Pure Appl. Phys. 12 (1974) 300-303.

[25] R.Shankar, R.A.Yadav, I.S.Singh, O.S.Singh,J . Pure Appl. Phys. 23 (1985) 339-345

[26] M. H.Jamroz, J.Cz Dobrowolski, R.Brzozwski, J. Mol. Struct. 787 (2006) 172-185.

[27] L.J. Bellamy, The Infrared Spectra of Complex Molecules, (vol. 2, Chapman and Hall, London, 1980).

[28] S. Mancy,W.L. Peticoles, R.S. Toblas, Spectrochim. Acta 35A (1979) 315.

[29] A. Usha Rani, N. Sundaraganesan, M. Kurt, M. Cinar, M. Karabacak, Spectrochim. Acta A 75 (2010) 1523-1529.

[30] M. Karabacak, M. Kurt, M. Çinar, A. Çoruh, Mol. Phys. 107 (2009) 253-264.

[31] M. Karabacak, M. Cinar, Z. Unal, M. Kurt, J. Mol. Struct. 982 (2010) 22-27.

[32] V.S. Madhavan, H.T. Varghese, S. Mathew, J. Vinsova, C.Y. Panicker, Spectrochim. Acta A 72 (2009) 547-553.

[33] M. Rogojerova, G. Keresztury, B. Jordanova, Spectrochim. Acta A 61 (2005) 1661-1670.

[34] C.S. Hiremath, J. Yenagi, J. Tonannavar, Spectrochim. Acta A 68 (2007) 710-717.

[35] V. Sortur, J. Yenagi, J. Tonannavar, V.B. Jadhav, M.V. Kulkarni, Spectrochim. Acta A 71 (2008) $688-694$.

[36] D.H. Wiffen, Spectrochimica Acta 7 (1955) 253-256.

[37] V.Sortur, Jayashree Yenagi, J. Tonannavar, V.B. Jadhav, M.V. Kulkarni, Spectrochimica Acta A 71 (2008) 688-694

[38] J.H. Risgin, Fluorocarbons and related compounds, (Vol II. Academic press, New York, 1954) 449-452

[39] I. Fleming, Frontier Orbitals and Organic Chemical Reactions, (Wiley, London, 1976).

[40] D.Sajan,K.U.Lakshmi,Y.Erdogdu,I.H.Joe,Spectrochim, Acta 78A (2011) 113.

[41] B.Eren, A.Unal,Spectrochim, Acta Part A 103 (2013) 222-23.

[42] R.Parr,L.Szentpaly,S.Liu,Am,Chem.Soc.(121,1999) 1922-1924.

[43] P.Chattraj, B.Maiti, U.Sarkar, J.Phys.Chem.A107 (2003) 4973-4975.

[44] J.S. Murray, K. Sen, Molecular Electrostatic Potentials, Concepts and Applications, Elsevier, Amsterdam,1996.

[45] E.Scrocco, J.Tomasi, in:P.Lowdin(Ed), Advances in quantum chemistry.(Academic press, New York, 1978).

[46] J. Sponer, P. Hobza, Int. J. Quant. Chem. 57 (1996) 959.

[47] J. Bevan Ott, J. Boerio-Goates, Calculations from Statistical Thermodynamics, (Academic Press 2000).

[48] R. Zhang, B. Dub, G. Sun, Y. Sun, Spectrochim. Acta A 75 (2010) 1115-1124.

[49] M.Govindarajan, M.Karabacak, S.Periyandi, D.Tanuja, Spectrochim. Acta A 97 (2012) 231-245.

[50] C. James, A. AmalRaj, R. Reghunathan, I. Hubert Joe, V.S. JayaKumar, J. Raman Spectrosc. 37 (2006) 1381-1392.

[51] L.J. Na, C.Z. Rang, Y.S. Fang, J. Zhejiang Univ. Sci. 6B (2005) 584-589.

IOSR Journal of Applied Physics (IOSR-JAP) is UGC approved Journal with Sl. No. 5010, Journal no. 49054.

G.Shakila. "Spectroscopic Investigation (FT-IR, FT-RAMAN, UV and NMR), NBO, NLO Analysis and Fukui Function of 2, 5-Dichloroaniline by DFT Calculations." IOSR Journal of Applied Physics (IOSR-JAP) 9.4 (2017): 42-58. 